\title{
Molecular and Histopathological Changes Associated with Keratoconus
}

\author{
Mariam Lotfy Khaled, ${ }^{1}$ Inas Helwa, ${ }^{1}$ Michelle Drewry, ${ }^{1}$ Mutsa Seremwe, ${ }^{1}$ \\ Amy Estes, ${ }^{2,3}$ and Yutao Liu ${ }^{1,3,4}$ \\ ${ }^{1}$ Department of Cellular Biology and Anatomy, Augusta University, Augusta, GA, USA \\ ${ }^{2}$ Department of Ophthalmology, Augusta University, Augusta, GA, USA \\ ${ }^{3}$ James \& Jean Culver Vision Discovery Institute, Augusta University, Augusta, GA, USA \\ ${ }^{4}$ Center for Biotechnology and Genomic Medicine, Augusta University, Augusta, GA, USA \\ Correspondence should be addressed to Yutao Liu; YUTLIU@augusta.edu
}

Received 28 September 2016; Revised 16 December 2016; Accepted 4 January 2017; Published 30 January 2017

Academic Editor: Jose M. González-Meijome

Copyright (C) 2017 Mariam Lotfy Khaled et al. This is an open access article distributed under the Creative Commons Attribution License, which permits unrestricted use, distribution, and reproduction in any medium, provided the original work is properly cited.

\begin{abstract}
Keratoconus (KC) is a corneal thinning disorder that leads to loss of visual acuity through ectasia, opacity, and irregular astigmatism. It is one of the leading indicators for corneal transplantation in the Western countries. KC usually starts at puberty and progresses until the third or fourth decade; however its progression differs among patients. In the keratoconic cornea, all layers except the endothelium have been shown to have histopathological structural changes. Despite numerous studies in the last several decades, the mechanisms of $\mathrm{KC}$ development and progression remain unclear. Both genetic and environmental factors may contribute to the pathogenesis of $\mathrm{KC}$. Many previous articles have reviewed the genetic aspects of $\mathrm{KC}$, but in this review we summarize the histopathological features of different layers of cornea and discuss the differentially expressed proteins in the KC-affected cornea. This summary will help emphasize the major molecular defects in KC and identify additional research areas related to $\mathrm{KC}$, potentially opening up possibilities for novel methods of KC prevention and therapeutic intervention.
\end{abstract}

\section{Introduction}

The cornea is the outermost avascular and transparent part of the eye consisting of epithelium, Bowman's layer, stroma, Descemet's membrane, and endothelium. In 2013, a novel collagenous, acellular layer, the Dua layer, was identified between corneal stroma and Descemet's membrane [1]. Each layer has a specific important function, and a defect in any of these layers can lead to corneal disorders. The most common corneal ectatic disorder and a leading indicator for corneal transplantation in developed countries is keratoconus (KC) $[2,3] . \mathrm{KC}$ is a bilateral, progressive ectatic disease where the cornea becomes cone shaped due to significant thinning of the corneal stroma (Figure 1). Visual impairment develops from myopia and irregular astigmatism [4]. Early forms of KC can be more accurately detected and potentially quantified in a reproducible manner with corneal topography [5].

Although KC has long been described as a noninflammatory disorder, recent reports have indicated possible inflammatory mechanisms [6-8]. KC usually starts at puberty and progresses until it stabilizes in the third or fourth decade. An inverse correlation has been noticed between age and $\mathrm{KC}$ severity $[9,10]$. The earlier the onset of $\mathrm{KC}$, the more severe the clinical phenotypes. KC appears in all ethnicities and has no gender preference $[5,11]$. The prevalence of KC varies greatly worldwide; it was reported at $0.0003 \%$ in Russia [12], 0.086\% in Denmark [13], 0.249\% in Iran [14], and 2.3\% in central India [15]. Not only do geographical variations change KC prevalence, but also the source of the collected data does. For example, in the USA, the prevalence of $\mathrm{KC}$ was found to be $600 / 100,000$ in a population based study [16] and $54.5 / 100,000$ in a hospital records based study [17].

Many reviews have previously summarized the genetic studies linked to KC incidence [18, 19], whereas others have discussed the various advances in treatment modalities [20, 21]. Despite recent advances in $\mathrm{KC}$ research, the molecular and pathological mechanisms of KC still remain unclear. To 


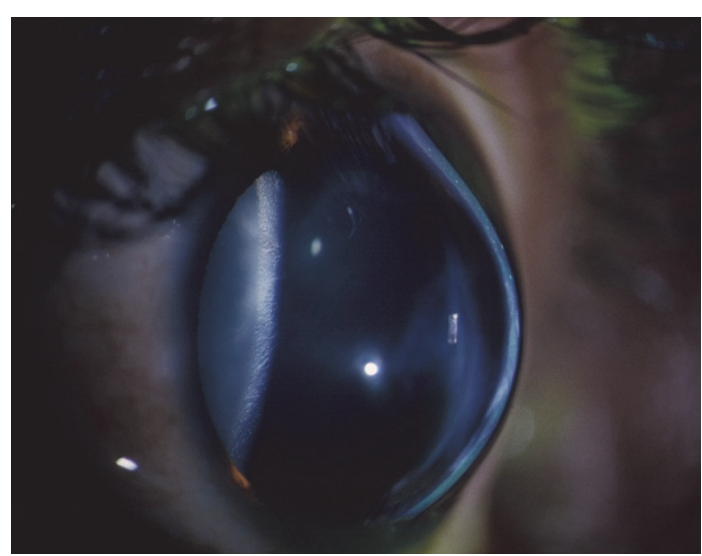

FIGURE 1: Cone shaped phenotype of the cornea in a keratoconus patient.

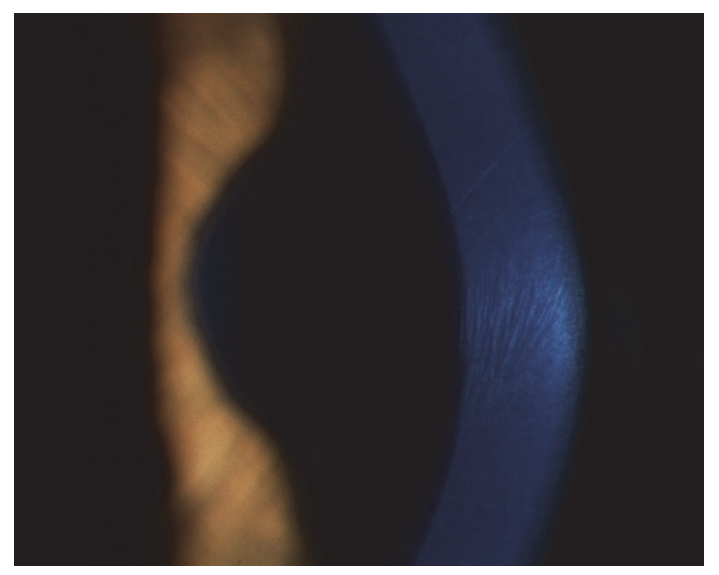

FIgURE 2: Sign of Vogt's striae showing fine vertical lines in deep stroma and Descemet's membrane of a keratoconus patient.

our knowledge, there is currently no comprehensive article that collectively summarizes the clinical and histopathological phenotypes associated with molecular and biochemical changes in $\mathrm{KC}$. We hope that a better understanding of pathological changes associated with $\mathrm{KC}$ may promote further research to identify novel therapeutic targets that could stop or delay KC progression.

1.1. Clinical Signs of KC. Clinically, the primary symptoms of $\mathrm{KC}$ are reduced visual acuity, photophobia, monocular diplopia, and glare. Due to disease progression, KC patients usually need frequent adjustment of their spectacle correction, and often vision cannot be corrected to 20/20 with spectacles alone [22]. In moderate to advanced $\mathrm{KC}$, slit lamp examination can often capture clinical signs of $\mathrm{KC}$, such as Fleischer's ring (iron lines partially or completely surrounding the cone), Vogt's striae (fine vertical lines in deep stroma and Descemet's membrane, Figure 2), corneal thinning, and Münson's sign (bulging of the lower lid during downgaze, Figure 3). Other accompanying signs that might appear are increased visibility of corneal nerves, apical thinning, anterior stromal clearing lines, subepithelial fibrillary

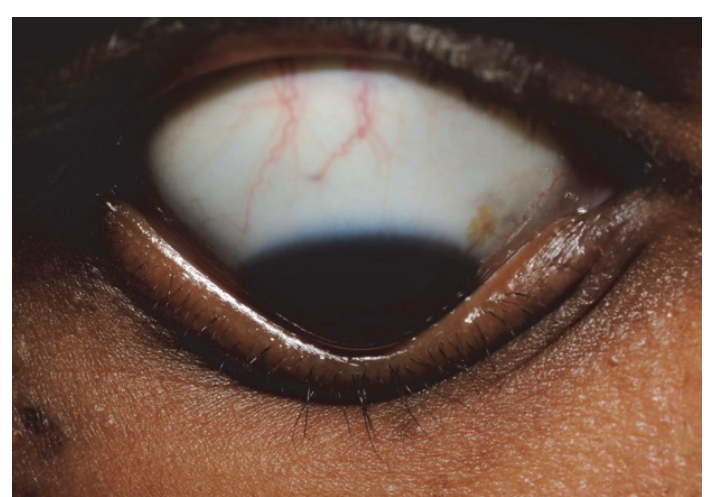

FIGURE 3: Münson's sign in a keratoconus patient which appears as bulging of the lower lid during downgaze.

lines, and central or eccentric corneal protrusion [5]. Corneal topography, a key diagnostic method for $\mathrm{KC}$, has greatly aided in diagnosis and treatment of $\mathrm{KC}$ and forme fruste, the subclinical presentation of $\mathrm{KC}$, leading to earlier treatment of these patients.

1.2. Etiology. $\mathrm{KC}$ is a complex multifactorial disorder, and changes in numerous genes and environmental factors are thought to be responsible for the disease development and progression [23].

1.2.1. Genetic Factors. The majority of KC cases are sporadic; however, $6-23.5 \%$ of keratoconic patients have a positive family history [24]. First-degree relatives of KC patients have a risk of developing $\mathrm{KC}$ that is 15-67 times higher than the general population [25]. The suggested pattern of inheritance in these familial cases is mostly autosomal dominant (reviewed in [18]). Monozygotic twins have been reported to be concordantly affected with $\mathrm{KC}$, rather than discordant for $\mathrm{KC}$, which is considered important evidence for genetic contribution in the pathogenesis of KC [26]. Wang et al. have suggested that $\mathrm{KC}$ is inherited likely due to a major gene defect [27], while Kriszt et al. have indicated that $\mathrm{KC}$ is a complex non-Mendelian disease [28]. Familybased linkage analyses have identified at least 17 genomic loci from 12 different studies [29-40]. Mutations in the MIR184 gene have been found to cause $\mathrm{KC}$, but the majority of the mutations remain to be identified (reviewed in [18]).

1.2.2. Environmental Factors. Besides genetic factors, many environmental factors have been documented as contributors to $\mathrm{KC}$ pathogenesis in patients with and without any family history [18]. These factors include contact lens wear [20], vigorous eye rubbing [41, 42], atopy [43-45], ultraviolet light exposure, and other factors that can be related to increased oxidative stress in the cornea $[46,47]$.

1.3. Other Disorders Associated with $\mathrm{KC}$. Usually $\mathrm{KC}$ is thought to be a sporadic disease; however, it has been described in association with many syndromes and diseases. Down syndrome patients were found in several studies to 
develop $\mathrm{KC}$ at a higher frequency [11, 25, 48-52], while other studies reported the absence of $\mathrm{KC}$ in this subset of patients [53-55]. Interestingly, studies of Down syndrome patients who are less than 18 years old observed less or no incidence of KC compared to controls [52-55], while adult Down syndrome patients had a greater prevalence of KC [50, $51,56,57]$. KC has also been associated with Leber congenital amaurosis. Up to $30 \%$ of Leber congenital amaurosis patients were reported to have $\mathrm{KC}$, possibly due to the mechanical effects produced by eye rubbing [58-61]. Previous studies have also linked $\mathrm{KC}$ with many connective tissue diseases, including but not limited to Ehlers-Danlos syndrome [62], osteogenesis imperfecta [63], mitral valve prolapse [64, 65], Mediterranean fever [66], and joint hypermobility disease [67]. In contrast, another study has shown lack of association between $\mathrm{KC}$ and mitral valve prolapse or joint hypermobility [68]. A negative association has been identified between diabetes mellitus and $\mathrm{KC}$ (i.e., a reduced risk of developing $\mathrm{KC}$ in diabetic patients) $[11,69,70]$. In patients with diabetes mellitus, high levels of glucose may cause glycosylation of corneal fibers and induce collagen cross-linking in the stroma, in turn preventing biomechanical weakening of the cornea and reducing the risks of ectasia and $\operatorname{KC}[69,71]$. Additionally, Nemet et al. have reported a strong correlation between $\mathrm{KC}$ and allergic immune disorders, as well as autoimmune diseases [43], adding evidence to the positive relationship between KC and inflammation. Dry eye symptoms, such as lowering in tear secretion, tear film break up time, and corneal sensitivity, have been reported in $\mathrm{KC}$ patients [72-74]. Impairment of the corneal sensory nerve activity [74], decreased mucin production in tears [73], or elevated inflammatory mediators have been proposed to account for these dry eye associated symptoms in KC patients [72].

\section{Histopathological Abnormalities in $\mathrm{KC}$}

The cornea is composed of six distinct layers: the outer stratified, squamous nonkeratinized epithelium, the acellular Bowman's layer, the inner connective tissue stroma with its resident keratocytes, the pre-Descemet's Dua layer, Descemet's membrane, and the cuboidal monolayered endothelium. The cornea is surrounded anteriorly by the tear film and posteriorly by aqueous humor. Maintenance of corneal shape and transparency is critical for optimizing the eye's refractive power [75]. Researchers have used a variety of different advanced techniques to evaluate major morphological corneal changes in KC patients [76-82]. Light microscopy, confocal microscopy, and optical coherence tomography (OCT) have been used to examine the cornea in vivo [76, 8386], while electron and light microscopy have been used to investigate fixed and processed corneal tissues in vitro $[84,87,88]$.

An in vitro study with $95 \mathrm{KC}$-affected cornea specimens has categorized keratoconic corneal tissues into two microscopic patterns: typical and atypical [88]. The typical pattern has both stromal and central epithelial thinning with multiple Bowman's layer breaks, while the atypical one lacks breaks in
Bowman's layer and has less thinning of the central epithelium [88]. The typical pattern has been identified in more than $80 \%$ of the corneas and is present in $72 \%$ of the patients with bilateral corneal transplants. Using OCT, an in vivo study by Sandali et al. proposed a classification system for KC using five distinct stages to characterize the keratoconic progression [85]. Patients in stage 1 have a thinner corneal epithelium and stroma at the conus than control. In stage 2, hyperreflective anomalies in Bowman's layer are noticed with thickening epithelium and opaque stroma. In stage 3 there is increased epithelial thickening and stromal thinning with disruptions in Bowman's layer. Stage 4 shows pan-stromal scarring, and finally, stage 5 is considered as the acute form of keratoconus (hydrops) with Descemet's membrane rupture and total corneal scar [85]. Brautaset et al. have proposed that $\mathrm{KC}$ is a pan-corneal thinning disorder based on the corneal thinning appearance in the peripheral and central ectatic region [86].

2.1. Corneal Epithelium. Corneal epithelium functions as a diffusion barrier to water and solutes and as a mechanical barrier to microorganisms. It is one of the most highly innervated parts of human body and accounts for approximately $10 \%$ of the corneal thickness. The epithelial cells tightly adhere to each other and to the basement membrane [75]. Various studies have reported that basal epithelial cells in KC patients exhibited enlargement, irregular arrangement, and a significant reduction in cell density when compared to the control group $[77-79,88]$. Though epithelial thickness is thought to be negatively correlated with the $\mathrm{KC}$ severity $[77,89]$, other studies have demonstrated either no significant change of corneal epithelium [80] or thickened corneal epithelium in $\mathrm{KC}$ patients [76, 90, 91]. Corneal epithelial apoptosis, resulting in epithelium thinning, could result from chronic epithelial injury due to various environmental risk factors and could result in the release of apoptotic cytokines [87, 92].

2.2. Nerve Fibers. Increased visibility of the nerve fibers on slit lamp examination is one of the characteristic signs of $\mathrm{KC}[93,94]$. Although thinning of the cornea is the main reason for this increased nerve visibility [95], several subsequent studies have identified morphological abnormalities in corneal nerves. In $\mathrm{KC}$, the architecture of the subbasal corneal nerve plexus (located between the Bowman layer and the basal epithelium) has been shown to have a fragmented plexus [96] and a reduced central nerve fiber density [97]. Additionally, localized nerve thickening has been observed in close proximity to breaks in Bowman's membrane with wrapping of anterior keratocytes around the nerve [98, 99].

2.3. Bowman's Layer. Bowman's layer, also known as the Anterior Limiting Lamina, is an acellular collagen fibril matrix at the interface between the corneal epithelium and the stroma [100]. The actual function of Bowman's layer is still unknown. Many mammals have no Bowman's layer, yet corneal stability is not compromised. In $\mathrm{KC}$, cellular components have been observed in Bowman's layer, despite typically being acellular [101]. Other studies have demonstrated ruptures within Bowman's layer $[81,88]$ and the coexistence of 
a proliferative collagenous tissue derived from the anterior stroma just beneath Bowman's layer [102]. Isolated Bowman's layer transplantation has reduced and stabilized corneal ectasia in eyes with progressive and advanced KC [103], but it remains unknown whether Bowman's layer contributes to the pathogenesis of $\mathrm{KC}$.

2.4. Stroma. Stroma (Substantia Propria) accounts for approximately $80 \%$ of the cornea thickness [100]. It is a highly organized collagenous matrix consisting of multiple collagenous lamellae and keratocytes. Keratocytes are specialized mesenchymal cells that reside between lamellae. Within each lamella, collagen fibrils are parallel, tightly packed, and highly uniform in diameter. This organized architecture is responsible for the transparency of the cornea, and any disruption in this organization results in a severely opaque cornea [104]. Stromal keratocytes secrete and maintain the stromal matrix components and account for $10 \%$ of the stromal volume [75]. In KC, a significant decrease in the number of lamellae without thickness alteration $[105,106]$ and the appearance of nonkeratocyte cells and tissue debris have been demonstrated [87]. These nonkeratocytes are agranular and may have a role in the break down and phagocytosis of corneal tissues [87]. Significant reduction has been reported in anterior and posterior keratocyte density [78, 80, 81, 87, 99].

The collagen lamellae at the anterior stroma of a normal cornea are interwoven and narrow and form a steep angle with Bowman's layer. With progression towards Descemet's membrane, these lamellae become wider and their angle relative to Bowman's layer becomes flattened [107]. However, in $\mathrm{KC}$ collagen lamellae are wider and form a smaller angle with Bowman's layer. It has been suggested that collagen lamellae are expanded in association with protrusion of the cone [107]. Stromal lamellae in KC-affected cornea undergo splitting into multiple bundles of collagen fibrils with loss of the anterior lamellae [108]. Since the ACTB gene encoding $\beta$ actin has been shown to be downregulated in $\mathrm{KC}[109,110]$, these data suggest that the decrease of stromal keratocytes in $\mathrm{KC}$ may contribute to the reduced expression of $\beta$-actin, destabilization of cytoskeleton, and finally the thinning and weakening of the stroma [110].

2.5. Descemet's Membrane. Descemet's membrane, also referred to as the Posterior Limiting Lamina [100], is the membrane which separates the endothelial layer from the stroma. Like Bowman's layer, it is an acellular layer and is not continuous with the collagen fibrils of the stroma. Ruptures of Descemet's membrane have been observed in KC [111]. The common morphological folds and irregularities in Descemet's membrane do not show any consistent alterations with its extracellular matrix components [47]. Apparent Descemet's folds have been found in $8.3 \%$ of the $\mathrm{KC}$ cases associated with pleomorphism (variation in shape) or polymegethism (variation in size) of endothelial cells [91]. Rupture in Descemet's membrane with entering of aqueous humor into corneal epithelium and stroma is a serious complication for $\mathrm{KC}$, which is known as acute corneal hydrops [112]. Sutures in either Descemet's membrane or Dua layer have been reported as an efficient surgical treatment for acute hydrops $[113,114]$.

2.6. Endothelium. The endothelium is a monolayer of regularly sized polygonal cells, which mainly function to regulate the water content of corneal stroma. In several studies, this layer does not exhibit any changes during $\mathrm{KC}$ progression $[79,83,85,115]$. Conversely, some studies have reported slight increase in endothelial cell density in $\mathrm{KC}$ [72], while others have shown significant decrease in moderate to severe $\mathrm{KC}$ $[78,91]$. Several studies have demonstrated that endothelial cells in the peripheral region have a higher density than those in the central region [80,116-119], suggesting that human corneal endothelial stem/progenitor cells are mainly distributed in the periphery [120]. These studies emphasize the necessity of determining whether the endothelial morphological changes in $\mathrm{KC}$ are within the center or the periphery of the cornea $[76,83]$.

Additionally, clinical treatment supports the lack of endothelium involvement in KC pathogenesis. Penetrating keratoplasty $(\mathrm{PK})$ is a surgical procedure involving the removal of a full thickness portion of corneal tissue. In patients with KC, deep anterior lamellar keratoplasty (DALK) is considered an excellent alternative surgical option to PK. DALK preserves patient's endothelial layer, reducing their risk of graft rejection [121]. The preference of DALK in KC patients suggests that the most affected corneal layers in $\mathrm{KC}$ are the corneal epithelium and stroma. Histopathological changes in corneal layers other than epithelium and stroma may be secondary to the epithelial and stromal wound healing process $[47,88,122]$.

Collagen cross-linking (CXL) and intrastromal corneal ring segments implantation (ICRS) are alternative procedures for KC treatment. CXL uses riboflavin and ultraviolet-A rays to stop the progression of $\mathrm{KC}$ via increasing corneal biomechanical resistance $[123,124]$. Postoperatively, confocal microscopy has been used to examine corneal changes that may occur after CXL. Histopathological changes such as demarcation lines, keratocytes apoptosis, and stromal edema have been reported to disappear within 6 months, with improvement in the visual acuity; thus CXL has been considered as an effective and safe procedure $[125,126]$. ICRS implantation is a reversible, minimally invasive procedure for moderate $\mathrm{KC}$ without central corneal opacities. ICRS corrects corneal ectasia via shortening the cone length, causing corneal flattening to the periphery [127]. Improvements in the refractive power, topographic measurements, and optical quality have been reported postoperatively, with an increase in contact lens tolerability [127-129]. Complications, such as segment extrusion, segment migration, or shadow effects, have been found to be rare among patients [127].

\section{Disrupted Corneal Homeostasis and KC}

$\mathrm{KC}$ is known to be degenerative and progressive. Homeostasis of the corneal microenvironment is controlled and balanced through various molecular mechanisms; however, the main molecular mechanisms that contribute to the structural and 
biochemical abnormalities in $\mathrm{KC}$ are still unclear. In this section, we summarize the documented molecular changes associated with $\mathrm{KC}$ and their impact on the integrity and transparency of the cornea.

3.1. WNT and HH Proteins. The WNT and Hedgehog $(\mathrm{HH})$ proteins are secreted proteins that regulate a variety of developmental processes in vertebrates and invertebrates by inducing transcriptional or morphological changes in responding cells $[130,131]$. It is well documented that WNT and $\mathrm{HH}$ signaling controls stem cell differentiation [132-134]. Inappropriate activation of $\mathrm{WNT}$ and $\mathrm{HH}$ signaling pathways can lead to various diseases $[135,136]$. Few studies have been done to determine the role of those signaling pathways in the progression of the KC $[137,138]$.

Cornea epithelial cells undergo continuous renewal from limbal stem cells [139], and a deficiency in self-renewal can lead to deleterious effects on corneal wound healing and surface integrity [140]. Furthermore, improper differentiation of these stem cells can give rise to keratinized, nontransparent corneal epithelium [137]. An in vitro study has shown that the $\mathrm{HH}$ and WNT pathways are necessary to maintain corneal endothelial cell integrity and structure [120]. Knockdown of WNT7A switches corneal epithelial cells to skinlike epidermal cells and negatively affects the transparency of the cornea, suggesting its involvement in corneal epithelium differentiation [137]. Recently, a missense coding variant (rs121908120, c.1145T>A, p.228Phe >Ile) in the WNT10A gene has been associated with $\mathrm{KC}$ via decreased corneal thickness [138]. An intronic variant rs10453441 in the WNT7B gene has been associated with central cornea thickness [141]. These data illustrate the functional involvement of WNT pathway components in the pathogenesis of $\mathrm{KC}$.

3.2. Cellular Adhesion Molecules (CAM). Cellular adhesion molecules (CAM) are cell surface receptors that play important roles in various cell-cell and cell-extracellular matrix interactions in the cornea. $\mathrm{KC}$ is associated with various defects in corneal layer structure and integrity, which may be related to a disturbance in the expression of CAMs in the cornea. It has been previously reported that CD34, a CAM and a hematopoietic stem cell marker, is expressed in normal human corneal keratocytes [142]. By studying healthy versus diseased corneal samples including $\mathrm{KC}$, it has been demonstrated that the loss of CD34 immunoreactivity seems to be a constant feature and early event in KC [143].

Another CAM, Desmoglein 3 (DSG3), is a desmosomal cadherin that mediates cell-cell adhesion via desmosomes [144]. Nielsen et al. have reported significantly increased DSG3 in the mRNA and protein levels in all of the KC samples studied [145].

Laminin and fibronectin are CAMs essential for the binding of basal epithelial cells to the basement membrane via integrins. Earlier studies have demonstrated overexpression of fibronectin in scarred areas of the anterior $\mathrm{KC}$ cornea [47, 146]. Similarly, Deng and colleagues have observed increased staining of fibronectin in the basement membrane of corneal epithelial cells, especially in regions of scarring
[147]. Upregulation of DSG3, laminin, fibronectin, and other types of CAM in KC could be downstream events of the wound healing cascade.

Corneal wound healing is a complex process. It involves the integrated actions of multiple growth factors, cytokines and proteases produced by epithelial cells, stromal keratocytes, and inflammatory cells [148]. Following an epithelial insult, various cytokines are released to induce a cascade of events in an attempt to repair the epithelial defect and modulate remodeling of the stroma, minimizing loss of transparency and function. However, an unregulated process of wound repair could result in disease [148]. In 2001, Deng et al. have proposed that a process similar to wound healing may contribute to the changes seen in the KC patients [147].

3.3. Collagen and Proteoglycans in KC. The cornea has at least 11 types of collagen. Within the corneal extracellular matrix (ECM), collagen interacts mainly with two types of proteoglycans: keratan sulfate (the major proteoglycan in the cornea by 60\%) and chondroitin/dermatan sulfate. Proteoglycans consist of a core protein and a glycosaminoglycan side chain. In keratan sulfate, the main core proteins are keratocan, which is unique to the cornea, lumican, and fibromodulin. For the chondroitin/dermatan sulfate, the primary core proteins are decorin and biglycan $[75,149,150]$. As mentioned earlier, the transparency of cornea requires uniform orientation of collagen fibers in the corneal matrix, and normal expression of proteoglycans is essential for this organized architecture [75].

In $\mathrm{KC}$, components of the ECM have been shown to have altered expression levels or abnormal localizations [47, 151]. Many proteomic studies have identified differences in the abundance of proteins between normal and keratoconic corneas (Table 1). Lumican and keratocan have been shown to be significantly decreased in KC $[152,153]$, yet keratocan has been reported to be highly expressed in the stroma of $\mathrm{KC}$ compared to normal or other diseased cornea samples, such as from Fuchs' corneal dystrophy or pseudophakic bullous keratopathy patients [154]. Joseph and colleagues, using the shotgun proteomics method, have further confirmed a 2.4fold increase of the stromal keratocan in KC patients [155]. Collagen types I, III, V, and XII have been identified to have a lower expression level in KC [152]. Reduction in the collagen components might be related to a defect in the hydroxylation of proline due to endoplasmic reticulum stress or chaperone defects [152]. Collagen synthesis abnormality has been also linked to decreased amount of sulfated glycosaminoglycan, especially heparan sulfate, on the stromal cell surface [156158]. Although many studies (Table 1) have demonstrated contradictory expression levels of the ECM components, these studies indicate the possible disruption in the molecular mechanisms regulating ECM homeostasis.

3.4. Degradative Enzymes and Their Inhibitors. A balanced equilibrium between degradative enzymes and their inhibitors is required for microenvironment homeostasis. Many KC studies have documented that the disruption of this homeostasis is due to an upregulation of the degradative 
TABLE 1: List of proteins with expression change in cornea samples affected with keratoconus.

\begin{tabular}{|c|c|c|c|c|c|}
\hline Protein name & Functions & Corneal layer & Method of detection & $\begin{array}{l}\text { Expression } \\
\text { change }\end{array}$ & Reference \\
\hline $\begin{array}{l}\text { Superoxide } \\
\text { dismutase }\end{array}$ & $\begin{array}{l}\text { Antioxidant enzyme that can } \\
\text { metabolize superoxide radicle }\end{array}$ & $\begin{array}{l}\text { Central portion of the } \\
\text { cornea }\end{array}$ & ELISA & Decreased & [188] \\
\hline $\begin{array}{l}\text { Annexin A2 } \\
\text { Annexin A8 }\end{array}$ & $\begin{array}{l}\text { Involved in cellular growth } \\
\text { regulation and in signal } \\
\text { transduction pathways }\end{array}$ & Epithelium & 2D-DIGE & $\begin{array}{l}\text { Decreased } \\
\text { Increased }\end{array}$ & {$[155]$} \\
\hline $\begin{array}{l}\text { Carbonic } \\
\text { anhydrase I }\end{array}$ & $\begin{array}{l}\text { Playing a role in the barrier } \\
\text { function of corneal endothelium }\end{array}$ & Stroma & $\begin{array}{l}\text { Nano-ESI-LC-MS } \\
(\mathrm{MS})^{2}\end{array}$ & Decreased & {$[152]$} \\
\hline $\begin{array}{l}\text { Collagen I } \alpha 1 \\
\text { Collagen I } \alpha 2\end{array}$ & Structural protein & Epithelium & $\begin{array}{l}\text { Nano-ESI-LC-MS } \\
(\mathrm{MS})^{2}\end{array}$ & Decreased & {$[152]$} \\
\hline Cathepsin B & $\begin{array}{l}\text { Member of corneal epithelial } \\
\text { lysosomal proteases }\end{array}$ & $\begin{array}{l}\text { Epithelium and } \\
\text { stroma; tears }\end{array}$ & IM; MF10-LTQ-FT MS & Increased & {$[159,162]$} \\
\hline Vimentin & A type of intermediate filament & Stroma; epithelium & $\begin{array}{c}\text { Nano-ESI-LC-MS } \\
(\mathrm{MS})^{2}\end{array}$ & Increased & {$[152,155]$} \\
\hline Keratocan & $\begin{array}{l}\text { Proteoglycan protein, unique for } \\
\text { cornea }\end{array}$ & Stroma & $\begin{array}{l}\text { IM, Nano-ESI-LC-MS } \\
(\mathrm{MS})^{2}\end{array}$ & Increased & {$[154,155]$} \\
\hline Serotransferrin & Iron binding transport proteins & Stroma & $\begin{array}{c}\text { Nano-ESI-LC-MS } \\
(\mathrm{MS})^{2}\end{array}$ & Decreased & {$[155]$} \\
\hline Transketolase & $\begin{array}{l}\text { Enzyme in the nonoxidative } \\
\text { branch of the pentose-phosphate } \\
\text { pathway }\end{array}$ & Epithelium & $\begin{array}{l}\text { Nano-ESI-LC-MS } \\
(\mathrm{MS})^{2}\end{array}$ & Decreased & {$[155]$} \\
\hline $\begin{array}{l}\text { Phosphoglycerate } \\
\text { kinase } 1\end{array}$ & $\begin{array}{l}\text { ATP-generating glycolytic } \\
\text { enzyme }\end{array}$ & Epithelium & $\begin{array}{l}\text { Nano-ESI-LC-MS } \\
(\mathrm{MS})^{2}\end{array}$ & Decreased & {$[155]$} \\
\hline NADPH oxidase & $\begin{array}{l}\text { Alarm system for cellular stress } \\
\text { response }\end{array}$ & Epithelium & $\begin{array}{l}\text { Nano-ESI-LC-MS } \\
(\mathrm{MS})^{2}\end{array}$ & Decreased & {$[155]$} \\
\hline $\begin{array}{l}\text { NADPH } \\
\text { menadione } \\
\text { oxidoreductase } 1\end{array}$ & $\begin{array}{l}\text { Reducing menadione into a } \\
\text { stable hydroquinone that can be } \\
\text { readily conjugated and excreted }\end{array}$ & Epithelium & $\begin{array}{l}\text { Nano-ESI-LC-MS } \\
(\mathrm{MS})^{2}\end{array}$ & Decreased & {$[155]$} \\
\hline Heat shock B1 & $\begin{array}{l}\text { Involved in stress resistance and } \\
\text { actin organization }\end{array}$ & Epithelium & 2D-DIGE & Decreased & {$[155]$} \\
\hline $\mathrm{S} 100-\mathrm{A} 4$ & $\begin{array}{l}\text { Binding to several components of } \\
\text { the cytoskeleton }\end{array}$ & Epithelium & $\begin{array}{l}\text { WB and IM; 2D-DIGE; } \\
\text { Nano-ESI-LC-MS } \\
(\mathrm{MS})^{2}\end{array}$ & Increased & {$[145,152,155]$} \\
\hline Keratin 1 & Structural protein & Epithelium & $\begin{array}{c}\text { Nano-ESI-LC-MS } \\
(\mathrm{MS})^{2}\end{array}$ & Increased & {$[155]$} \\
\hline Keratin 6A & Structural protein & Epithelium & $\begin{array}{l}\text { Nano-ESI-LC-MS } \\
(\mathrm{MS})^{2}\end{array}$ & Increased & {$[152]$} \\
\hline Keratin 16 & Structural protein & Epithelium & $\begin{array}{l}\text { Nano-ESI-LC-MS } \\
(\mathrm{MS})^{2}\end{array}$ & Increased & [152] \\
\hline Desmoglein 3 & Cell adhesion molecule & Epithelium & WB and IM & Increased & [145] \\
\hline Decorin & Proteoglycan core protein & Stroma & $\begin{array}{l}\text { IM; Nano-ESI-LC-MS } \\
(\mathrm{MS})^{2}\end{array}$ & Increased & {$[154,155]$} \\
\hline $\begin{array}{l}\text { Collagen VI } \alpha 1 \text {, } \\
\text { Collagen VI } \alpha 2, \\
\text { and Collagen VI } \alpha 3\end{array}$ & Structural protein & Epithelium & $\begin{array}{l}\text { Nano-ESI-LC-MS } \\
(\mathrm{MS})^{2}\end{array}$ & Decreased & {$[152]$} \\
\hline Collagen VII $\alpha 1$ & Structural protein & Epithelium & $\begin{array}{l}\text { Nano-ESI-LC-MS } \\
(\mathrm{MS})^{2}\end{array}$ & Decreased & {$[152]$} \\
\hline Lactoferrin & Iron binding transport proteins & Tears; epithelium & $\begin{array}{l}\text { 2D-DIGE; } \\
\text { Nano-ESI-LC-MS } \\
(\mathrm{MS})^{2}\end{array}$ & Decreased & $\begin{array}{l}{[152,208,} \\
209]\end{array}$ \\
\hline Lipocalin 1 & $\begin{array}{l}\text { Major lipid-binding protein in } \\
\text { tears }\end{array}$ & Stroma & $\begin{array}{l}\text { Nano-ESI-LC-MS } \\
(\mathrm{MS})^{2}\end{array}$ & Decreased & [152] \\
\hline $\begin{array}{l}\text { Hepatocyte growth } \\
\text { factor }\end{array}$ & $\begin{array}{l}\text { Regulating cell growth and } \\
\text { motility }\end{array}$ & Epithelium & IM & Increased & [186] \\
\hline
\end{tabular}

Nano-ESI-LC-MS (MS) ${ }^{2}$ : Nano-Electrospray Ionization Liquid Chromatography Tandem Mass Spectrometry; 2D-DIGE: two-dimensional-difference gel electrophoresis coupled with mass spectrometric methods; IM: immunostaining; WB: Western blot; MF10-LTQ-FT MS: prefractionating and enriching the proteins followed by linear ion trap quadrupole Fourier transform mass spectrometer. 
enzymes and a downregulation of their inhibitors. It is thought that this disruption may mediate the pathological progression of KC through degradation of the ECM in the cornea, resulting in corneal thinning $[46,159,160]$.

Lysosomal enzymes, such as acid esterases, acid phosphatases, and acid lipases, have been shown to have higher expression in the epithelium, stroma, and endothelium of patients with KC [161]. Moreover, cathepsins B and G, which are proteases in lysosomes and activate caspases, have been shown to have elevated expression within the keratocytes of KC corneas [101, 159]. Cathepsin B has also been shown to be overexpressed in tears of $\mathrm{KC}$ patients, and it has been proposed that these cathepsins may play a vital role in apoptosis of keratocytes in KC [162].

Matrix metalloproteinases (MMPs) have also been reported to be highly upregulated in $\mathrm{KC}$ (reviewed in [163]). MMPs are a large family of calcium-dependent, zinccontaining endopeptidases. MMPs are classified according to substrate preference into subfamilies including collagenases, gelatinases, stromelysins, matrilysins, and membrane-type MMPs [164]. Under normal physiological conditions, MMPs are minimally expressed and are responsible for tissue remodeling and degradation of the ECM [165]. Many studies have reported altered expression of MMPs in KC (reviewed in $[160,163,166])$. Shetty et al. showed that MMP-9 was significantly overexpressed (along with IL- 6 and TNF- $\alpha$ ) in patients' corneal epithelial cells [167]. Interestingly, this upregulation of MMP-9, IL-6, and TNF- $\alpha$ was reversed successfully upon treatment with Cyclosporine A (immunosuppressant drug), which may help in arresting disease progression [167]. MMP-9 has also been shown to be elevated in tears of $\mathrm{KC}$ $[167,168]$; however, it had normal expression in subclinical KC patients [168]. Another study showed elevated levels of MMP-1, MMP-3, MMP-7, and MMP-13 in KC patients' tears [169]. The proteinase inhibitors, on the other hand, have been reported to be downregulated in KC. These inhibitors mainly include $\alpha 1$-protease inhibitor, $\alpha 2$-macroglobulin, and tissue inhibitors of MMP $[160,170,171]$.

3.5. Inflammation and KC. Various factors have been suggested to cause inflammation for $\mathrm{KC}$ patients. Contact lenses, used as treatment for mild to moderate $\mathrm{KC}$, have been reported to cause the elevation of proinflammatory cytokines in KC patients' tears [172, 173] and to cause dry eye exacerbation [174]. Abnormal eye rubbing has been hypothesized to increase $\mathrm{KC}$ progression via aggravating corneal deformities and inflammation [175-177]. Although CXL is considered as an effective treatment for moderate to severe KC $[126,178]$, acute inflammatory response, allergic conjunctivitis, and bacterial infection have been reported after CXL [179-181]. Examining tears from patients with KC or those who underwent CXL treatment, Balasubramanian et al. have found significant elevations in many cytokines (IL4, IL-5, IL-6, IL-8, TNF- $\alpha$, and TNF- $\beta$ ) in tears from KC patients and only significant elevation of TNF- $\alpha$ in the CXL treated group compared with controls [169]. Recruitment of immunoinflammatory cells (macrophages, leucocytes, and antigen presenting cells) has been observed in the epithelium and stroma of keratoconic cornea [182]. A known marker for systemic inflammation (neutrophil to lymphocyte ratio) has been found to be significantly higher in the serum of patients with progressive KC [183]. Additionally, TGF- $\beta 2$ has been found to be elevated in both aqueous humor and corneal epithelial cells in KC $[184,185]$. Basal epithelial cells of keratoconic cornea showed moderate-to-strong immunoreactivity for hepatocyte growth factor and its receptor (c-met) [186]. These data indicate that alterations in homeostasis may be attributed to dysregulation in inflammatory mediators, such as cytokines (IL-6, IL-1, IL-17, and TNF- $\alpha$ ) and growth factors (TGF- $\beta$, VEGF, and NGF), supporting the potential involvement of chronic inflammation in the pathogenesis of $\mathrm{KC}[6,7]$.

3.6. Oxidative Stress. Cellular stress is induced by a sudden disruption of the cellular physiological local environment, compromising cell survival. Through various mechanisms, cells attempt to remove stressors, decrease damage, and maintain or reestablish homeostasis. However, various internal deleterious changes can happen during this process [187]. In 2003, Kenney and Brown hypothesized the existence of a relationship between corneal defects and the scavenging of reactive oxygen species. This was associated with the progressive events in $\mathrm{KC}$ that eventually led to oxidative corneal tissue damage [46]. Many proteins that are involved in free radical detoxification, such as glutathione, paraoxonase 1 , catalase, superoxide dismutase, and superoxide glutathione, have been shown to have decreased activity in $\mathrm{KC}[188,189]$.

3.6.1. Aldehyde Dehydrogenase. One of the important detoxifying enzymes that may be involved in $\mathrm{KC}$ is aldehyde dehydrogenase 3 (ALDH3). ALDH3 is dimeric zinc metalloenzyme that catalyzes the reversible oxidation of alcohols to aldehydes. ALDH3 accounts for approximately $20-40 \%$ of the soluble protein content in corneal epithelial cells of mammals (reviewed in [190]). ALDH3 directly absorbs UV light and removes cytotoxic aldehydes produced by UV-induced lipid peroxidation [191]. Mice with defective ALDH3 have been reported to be susceptible to UV-induced corneal clouding [192]. Lack of ALDH3 may lead to lipid peroxidation through UV-induced oxidative destruction of cell membranes and accumulation of cytotoxic aldehydes, such as malondialdehyde (MDA) [193]. A significant and distinct staining for MDA has been identified in 26 corneal tissues with $\mathrm{KC}$ but not in healthy tissues [194]. This data suggests that the presence of $\mathrm{MDA}$ in the $\mathrm{KC}$ corneal tissues may result from low expression of ALDH3 in these samples [194]. Another ALDH member, ALDH1B, has been reported by Mootha et al. to have a 212-fold reduced expression levels of both mRNA and protein in fibroblasts from KC patients [195].

3.6.2. Oxidoreductase. Oxidoreductases catalyze the transfer of electrons from electron donors to electron acceptors, and many of them have been identified as potential sources of superoxide anions in mammalian cells [187]. NADPH dehydrogenase is an oxidoreductase catalyzing the production of reactive oxygen species (ROS) [196]. Studies have discovered 
that acute exposure of keratinocytes to UV can lead to rapid activation of NADPH dehydrogenase and generation of ROS, which may have distinct physiologic importance [197199]. NADPH dehydrogenase may represent a cellular "alarm system" that can alert and prime the cells to either adapt to the stress or undergo apoptosis [187]. It has been reported that there is a 7-fold decrease in the expression of NADPH dehydrogenase and NADPH menadione oxidoreductase in KCaffected corneal epitheliums [155]. This significant expression reduction may be one of the pathways through which UV rays affect the progression of $\mathrm{KC}$.

3.6.3. Mitochondrial DNA. Another consequence of corneal oxidative stress is damage to mitochondrial DNA (mtDNA), which has been previously observed in KC corneal tissue [200]. mtDNA is a covalently closed, double-stranded molecule and is located in close proximity to the respiratory chains, which are the main cellular source of ROS. Mitochondrial dysfunction and mtDNA damage, in response to oxidative stressors, have been identified in cultured KC fibroblasts [201]. In human colorectal carcinoma cells, oxidative stress has been reported to lead to the degradation of mtDNA [202].

3.7. Lactoferrin/Transferrin. Fleischer's ring, or iron deposition at the base of the cone in the cornea, is a common clinical sign of KC [203]. Physiologically, healthy corneas need iron for the completion of the citric acid cycle and production of ATP, and iron is also an essential component of the rate-limiting enzyme in DNA synthesis [204]. Because iron is necessary in many corneal functions, disruptions in iron homeostasis and elevations in its level can lead to corneal disease [205]. Iron is present extracellularly in the tear film on the surface of the cornea. Iron is carried by two iron binding glycoproteins, lactoferrin and transferrin. These glycoproteins are found in many mucosal fluids, including tears [206, 207]. Through binding to iron, lactoferrin helps regulate iron levels, prevent oxidative damage, and strengthen the cornea's antibacterial defenses [205]. Decreased expression of lactoferrin has been reported in KC corneal epithelial cells [152]. Several studies have also reported lower expression of lactoferrin in the tears collected from KC patients [169, 208, 209], and transferrin has been shown to be expressed at lower levels in the corneal stroma in patients with $\mathrm{KC} \mathrm{[155].} \mathrm{All} \mathrm{these} \mathrm{data}$ indicate that reduced expression of iron binding proteins may contribute to deposition of iron in the cornea of $\mathrm{KC}$ patients.

Although numerous studies have been done to either investigate the mechanism underlying the progression of $\mathrm{KC}$ or report the histopathological changes in $\mathrm{KC}$ corneas, some of the results are contradictory. This could be due to many factors. The first factor is inconsistency in the different types of cornea samples, such as whole cornea, epithelium, stromal layer, or keratocytes, used in the various studies. The second factor is the usage of original host tissues versus cultured cells from KC cornea, and the third factor is the variation in the experimental platforms used to investigate the expression of selected proteins. For example, quantifying a specific protein known to be expressed among the different corneal layers could be misleading, because the expression of specific proteins in the different corneal layers could vary during the progression of $\mathrm{KC}$. To better understand $\mathrm{KC}$, we need to standardize the reporting of expression levels for our target and their location within the cornea, especially since previous studies have identified abnormal location and expression of certain proteins in different corneal layers in KC (Table 1). This underlines the importance of taking into account the part of the cornea used for the analysis as the differential protein expression differs from one layer to another.

\section{Hormones in $\mathrm{KC}$}

Sex steroid hormones, namely estrogen, progesterone, and testosterone, are produced by ovaries in females and testes in males. Although they circulate through blood, their effects rely on the receptors present in specific tissues and organs. These receptors are widely expressed in different ocular tissues, including the cornea. Corneal tissues express estrogen receptors types $\alpha$ and $\beta$, progesterone receptors, and androgen receptors. However, the mechanism through which hormones regulate corneal homeostasis still remains unclear (reviewed in [210]).

Previously, the development of $\mathrm{KC}$ has been proposed to be correlated with the hormonal changes that occur during puberty, pregnancy, or menopause [211-213]. However, the clinical information related to sex hormones for patients with $\mathrm{KC}$ is often limited, presenting a significant barrier to further study. In 2010, Fink et al. studied the effects of gender and hormone status on the severity and progression of $\mathrm{KC}$ in both men and women over a 3-year period [214]. This study grouped women into hormone-active and hormone-inactive groups during menopausal transition but failed to identify any significant difference in KC progression between these groups [214].

Conversely, there have been other reported cases in which pregnancy has induced the progression of $\mathrm{KC}[212,213,215]$, and some studies have postulated that pregnancy may be considered a risk factor for $\mathrm{KC}[212,215]$. The hormonal changes that occur during pregnancy had a negative impact on corneal biomechanics, as measured by changes in corneal topography $[212,215]$. Hoogewoud et al. have reported that, during the gestational period, women have experienced a significant progression in $\mathrm{KC}$, as indicated by a decrease in corrected distance visual acuity (CDVA) and reversible fluctuations in corneal topography [213]. Another large study has reported a similar decrease in CDVA during pregnancy, but changes returned to normal postpartum once the lactation period ended [216]. Women's use of contraceptives has also been reported to have an effect on the curvature of the cornea $[217,218]$.

Based on the expression pattern of $\alpha$ and $\beta$ estrogen receptors in corneal cells, it has been postulated that estrogen is supplied through tears and aqueous humor at concentrations that are approximately half the concentrations found in plasma [219]. The proposed mode of action of these steroidal hormones is via the regulation of gene expression in the nucleus, leading to changes in the concentration of ECM proteins, which are critical to the maintenance of corneal 
integrity [220]. It is plausible that estrogen may be responsible for weakening the cornea via the stimulation of MMPs and the release of prostaglandins, causing activation of proteolytic enzymes for collagen, disruption of collagen networks, and reduction in corneal-stiffness [220]. Recently, a study reported progression of $\mathrm{KC}$ in 6 eyes of 3 women after receiving an in vitro fertilization treatment which increases their estrogen levels [221]. Similarly, a recent study has identified a significant elevation in salivary dehydroepiandrosterone sulfate (DHEA-S, a common precursor to other androgens) levels and a decrease in estrone (a natural estrogen) level in KC patients independent of gender [222]. Elevated DHEA-S possibly increases the expression of specific cytokines (IL-16 and stem cell factors) by blocking endogenous glucocorticoid activity and stimulating the progression of KC [222]. However, no correlation has been detected between the increased salivary DHEA-S level and increased severity of KC [222].

Progesterone hormone, on the other hand, inhibits the prostaglandins that stimulate collagenases. Therefore, it is plausible that the stabilization in the cornea biomechanics during the last half of a normal pregnancy may be due to the action of progesterone, suggesting that progesterone may have a protective effect against the progression of $\mathrm{KC}$ during pregnancy [223]. Since there is a correlation between changes in corneal physiology and elevated levels of estrogen, $\mathrm{KC}$ may be triggered by elevated levels of estrogen coupled with a genetic disposition to a weaker cornea.

Moreover, some studies correlated KC progression with thyroxine hormone [224-227]. It was found that thyroxine levels were higher in tears of $\mathrm{KC}$ patients independent of their serum thyroxine level [225, 227]. Thyroxine has important roles in the differentiation, growth, metabolism, and physiological function of almost all tissues, including the cornea [228-230].

\section{Summary}

Keratoconus is a complex disorder with both genetic and environmental factors and may present as a secondary phenotype associated with other disorders. The disease progression of KC affects the epithelium, Bowman's layer, stroma, and Descemet's membrane of the cornea, but not the corneal endothelium. Extensive research in the histopathology of $\mathrm{KC}$ has provided critical information about the cellular and molecular mechanisms of $\mathrm{KC}$ pathogenesis (Figure 4). A number of proteins in several different pathways have been identified to have altered protein abundance in $\mathrm{KC}$-affected cornea samples (Figure 4). The primary corneal layer(s) with these abundance alterations will need to be determined. The lack of replication between different studies might be due to the following variables: different stages of $\mathrm{KC}$, sample size, detection technique, and statistical tools for data analysis. Animal models of $\mathrm{KC}$, which are currently lacking, will significantly promote our understanding of the pathogenesis of KC. A better understanding of the proteins and pathways involved in $\mathrm{KC}$ histopathogenesis may provide potential therapeutic targets for disease prevention and early diagnosis,

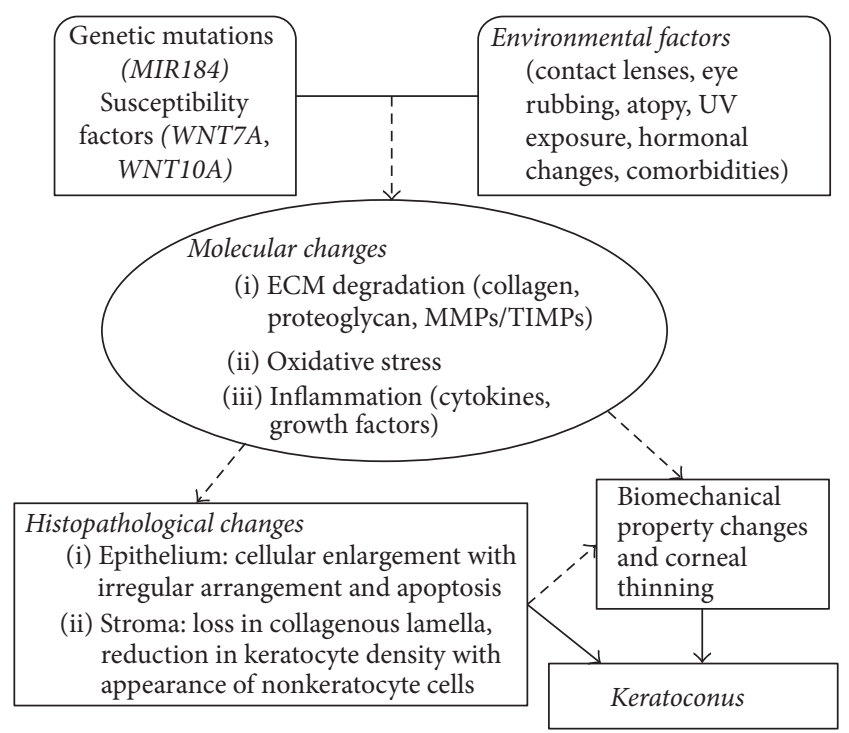

FIgURE 4: A potential physiological model for the pathogenesis of keratoconus.

thus delaying or arresting its progression and improving treatment of this severe vision threatening disorder.

\section{Competing Interests}

The authors declare that there is no conflict of interests regarding the publication of this paper.

\section{References}

[1] H. S. Dua, L. A. Faraj, D. G. Said, T. Gray, and J. Lowe, "Human corneal anatomy redefined: a novel pre-descemet's layer (Dua's Layer)," Ophthalmology, vol. 120, no. 9, pp. 1778-1785, 2013.

[2] P. C. Kang, G. K. Klintworth, T. Kim et al., "Trends in the indications for penetrating keratoplasty, 1980-2001," Cornea, vol. 24, no. 7, pp. 801-803, 2005.

[3] F. R. Ghosheh, F. A. Cremona, C. J. Rapuano et al., "Trends in penetrating keratoplasty in the United States 1980-2005," International Ophthalmology, vol. 28, no. 3, pp. 147-153, 2008.

[4] D. S. Tambe, A. Ivarsen, and J. Hjortdal, "Photorefractive Keratectomy in Keratoconus," Case Reports in Ophthalmology, vol. 6, no. 2, pp. 260-268, 2015.

[5] Y. S. Rabinowitz, "Keratoconus," Survey of Ophthalmology, vol. 42, no. 4, pp. 297-319, 1998.

[6] R. P. L. Wisse, J. J. W. Kuiper, R. Gans, S. Imhof, T. R. D. J. Radstake, and A. Van Der Lelij, "Cytokine expression in keratoconus and its corneal microenvironment: a systematic review," Ocular Surface, vol. 13, no. 4, pp. 272-283, 2015.

[7] V. Galvis, T. Sherwin, A. Tello, J. Merayo, R. Barrera, and A. Acera, "Keratoconus: an inflammatory disorder?" Eye (London, England), vol. 29, no. 7, pp. 843-859, 2015.

[8] C. Ionescu, C. G. Corbu, C. Tanase et al., "Inflammatory biomarkers profile as microenvironmental expression in keratoconus," Disease Markers, vol. 2016, Article ID 1243819, 8 pages, 2016. 
[9] S. J. Tuft, L. C. Moodaley, W. M. Gregory, C. R. Davison, and R. J. Buckley, "Prognostic factors for the progression of keratoconus," Ophthalmology, vol. 101, no. 3, pp. 439-447, 1994.

[10] A. Ertan and O. Muftuoglu, "Keratoconus clinical findings according to different age and gender groups," Cornea, vol. 27, no. 10, pp. 1109-1113, 2008.

[11] M. A. Woodward, T. S. Blachley, and J. D. Stein, "The association between sociodemographic factors, common systemic diseases, and keratoconus," Ophthalmology, vol. 123, no. 3, pp. 457465.e2, 2016.

[12] E. N. Gorskova and E. N. Sevost'ianov, "Epidemiology of keratoconus in the Urals," Vestnik Oftalmologii, vol. 114, no. 4, pp. 38-40, 1998.

[13] K. Nielsen, J. Hjortdal, E. A. Nohr, and N. Ehlers, "Incidence and prevalence of keratoconus in Denmark," Acta Ophthalmologica Scandinavica, vol. 85, no. 8, pp. 890-892, 2007.

[14] H. Ziaei, M. R. Jafarinasab, M. A. Javadi et al., "Epidemiology of keratoconus in an Iranian population," Cornea, vol. 31, no. 9, pp. 1044-1047, 2012.

[15] J. B. Jonas, V. Nangia, A. Matin, M. Kulkarni, and K. Bhojwani, "Prevalence and associations of keratoconus in rural maharashtra in central India: the central India eye and medical study," American Journal of Ophthalmology, vol. 148, no. 5, pp. 760-765, 2009.

[16] H. W. Hofstetter, "A keratoscopic survey of 13,395 eyes," American Journal of Optometry and Archives of American Academy of Optometry, vol. 36, no. 1, pp. 3-11, 1959.

[17] R. H. Kennedy, W. M. Bourne, and J. A. Dyer, "A 48-year clinical and epidemiologic study of keratoconus," American Journal of Ophthalmology, vol. 101, no. 3, pp. 267-273, 1986.

[18] J. Wheeler, M. A. Hauser, N. A. Afshari, R. R. Allingham, and Y. Liu, "The genetics of keratoconus: a review," Reproductive System \& Sexual Disorders, vol. 1, supplement 6, pp. 1-19, 2012.

[19] Y. Bykhovskaya, B. Margines, and Y. S. Rabinowitz, "Genetics in Keratoconus: where are we?" Eye and Vision, vol. 3, article 16, 2016.

[20] M. Romero-Jiménez, J. Santodomingo-Rubido, and J. S. Wolffsohn, "Keratoconus: a review," Contact Lens and Anterior Eye, vol. 33, no. 4, pp. 157-166, 2010.

[21] M. Farjadnia, M. Naderan, and M. Mohammadpour, "Gene therapy in keratoconus," Oman Journal of Ophthalmology, vol. 8, no. 1, pp. 3-8, 2015.

[22] G. Deepak, Keratoconus. A Clinical Update, Clinical, 2005.

[23] A. Gordon-Shaag, M. Millodot, E. Shneor, and Y. Liu, "The genetic and environmental factors for keratoconus," BioMed Research International, vol. 2015, Article ID 795738, 19 pages, 2015.

[24] F. Karimian, S. Aramesh, H. M. Rabei, M. A. Javadi, and N. Rafati, "Topographic evaluation of relatives of patients with keratoconus," Cornea, vol. 27, no. 8, pp. 874-878, 2008.

[25] Y. S. Rabinowitz, “The genetics of keratoconus," Ophthalmology Clinics of North America, vol. 16, no. 4, pp. 607-620, 2003.

[26] S. J. Tuft, H. Hassan, S. George, D. G. Frazer, C. E. Willoughby, and P. Liskova, "Keratoconus in 18 pairs of twins," Acta Ophthalmologica, vol. 90, no. 6, pp. e482-e486, 2012.

[27] Y. Wang, Y. S. Rabinowitz, J. I. Rotter, and H. Yang, "Genetic epidemiological study of keratoconus: evidence for major gene determination," The American Journal of Medical Genetics, vol. 93, no. 5, pp. 403-409, 2000.

[28] Á. Kriszt, G. Losonczy, A. Berta, G. Vereb, and L. Takács, "Segregation analysis suggests that keratoconus is a complex non-mendelian disease," Acta Ophthalmologica, vol. 92, no. 7, pp. e562-e568, 2014.

[29] M. Gajecka, U. Radhakrishna, D. Winters et al., "Localization of a gene for keratoconus to a 5.6-Mb interval on 13q32," Investigative Ophthalmology and Visual Science, vol. 50, no. 4, pp. 1531-1539, 2009.

[30] A. E. Hughes, D. P. Dash, A. J. Jackson, D. G. Frazer, and G. Silvestri, "Familial keratoconus with cataract: linkage to the long arm of chromosome 15 and exclusion of candidate genes," Investigative Ophthalmology \& Visual Science, vol. 44, no. 12, pp. 5063-5066, 2003.

[31] A. E. Hughes, D. T. Bradley, M. Campbell et al., "Mutation altering the miR-184 seed region causes familial keratoconus with cataract," American Journal of Human Genetics, vol. 89, no. 5, pp. 628-633, 2011.

[32] L. Bisceglia, P. De Bonis, C. Pizzicoli et al., "Linkage analysis in keratoconus: replication of locus $5 \mathrm{q} 21.2$ and identification of other suggestive loci," Investigative Ophthalmology \& Visual Science, vol. 50, no. 3, pp. 1081-1086, 2009.

[33] X. Li, Y. S. Rabinowitz, Y. G. Tang et al., "Two-stage genomewide linkage scan in keratoconus sib pair families," Investigative Ophthalmology \& Visual Science, vol. 47, no. 9, pp. 3791-3795, 2006.

[34] H. Tyynismaa, P. Sistonen, S. Tuupanen et al., "A locus for autosomal dominant keratoconus: Linkage to 16q22.3-q23.1 in Finnish families," Investigative Ophthalmology \& Visual Science, vol. 43, no. 10, pp. 3160-3164, 2002.

[35] Y. G. Tang, Y. S. Rabinowitz, K. D. Taylor et al., "Genomewide linkage scan in a multigeneration Caucasian pedigree identifies a novel locus for keratoconus on chromosome 5q14.3-q21.1," Genetics in Medicine, vol. 7, no. 6, pp. 397-405, 2005.

[36] H. Hutchings, H. Ginisty, M. Le Gallo et al., "Identification of a new locus for isolated familial keratoconus at 2p24," Journal of Medical Genetics, vol. 42, no. 1, pp. 88-94, 2005.

[37] F. Brancati, E. M. Valente, A. Sarkozy et al., "A locus for autosomal dominant keratoconus maps to human chromosome 3p14-q13," Journal of Medical Genetics, vol. 41, no. 3, pp. 188-192, 2004.

[38] P. Liskova, P. G. Hysi, N. Waseem et al., "Evidence for keratoconus susceptibility locus on chromosome 14: a genome-wide linkage screen using single-nucleotide polymorphism markers," Archives of Ophthalmology, vol. 128, no. 9, pp. 1191-1195, 2010.

[39] A. Hameed, S. Khaliq, M. Ismail et al., "A novel locus for Leber congenital amaurosis (LCA4) with anterior keratoconus mapping to chromosome 17p13," Investigative Ophthalmology and Visual Science, vol. 41, no. 3, pp. 629-633, 2000.

[40] J. Fullerton, P. Paprocki, S. Foote, D. A. Mackey, R. Williamson, and S. Forrest, "Identity-by-descent approach to gene localisation in eight individuals affected by keratoconus from northwest Tasmania, Australia," Human Genetics, vol. 110, no. 5, pp. 462-470, 2002.

[41] C. W. McMonnies, "Mechanisms of rubbing-related corneal trauma in keratoconus," Cornea, vol. 28, no. 6, pp. 607-615, 2009.

[42] M. Naderan, S. Shoar, F. Rezagholizadeh, M. Zolfaghari, and M. Naderan, "Characteristics and associations of keratoconus patients," Contact Lens and Anterior Eye, vol. 38, no. 3, pp. 199205, 2015.

[43] A. Y. Nemet, S. Vinker, I. Bahar, and I. Kaiserman, "The association of keratoconus with immune disorders," Cornea, vol. 29, no. 11, pp. 1261-1264, 2010. 
[44] I. Merdler, A. Hassidim, N. Sorkin, S. Shapira, Y. Gronovich, and Z. Korach, "Keratoconus and allergic diseases among Israeli adolescents between 2005 and 2013," Cornea, vol. 34, no. 5, pp. 525-529, 2015.

[45] K. H. Weed, C. J. MacEwen, T. Giles, J. Low, and C. N. J. McGhee, "The Dundee University Scottish Keratoconus study: demographics, corneal signs, associated diseases, and eye rubbing," Eye, vol. 22, no. 4, pp. 534-541, 2008.

[46] M. C. Kenney and D. J. Brown, "The cascade hypothesis of keratoconus," Contact Lens and Anterior Eye, vol. 26, no. 3, pp. 139-146, 2003.

[47] M. C. Kenney, A. B. Nesburn, R. E. Burgeson, R. J. Butkowski, and A. V. Ljubimov, "Abnormalities of the extracellular matrix in keratoconus corneas," Cornea, vol. 16, no. 3, pp. 345-351, 1997.

[48] J. F. Cullen and H. G. Butler, "Mongolism (down's syndrome) and keratoconus," The British journal of ophthalmology, vol. 47, pp. 321-330, 1963.

[49] G. Howells, "Mitral valve prolapse, keratoconus and Down's syndrome," Journal of the Royal Society of Medicine, vol. 85, no. 12, p. 773, 1992.

[50] D. Real De Asua, M. Quero, F. Moldenhauer, and C. Suarez, "Clinical profile and main comorbidities of Spanish adults with Down syndrome," European Journal of Internal Medicine, vol. 26, no. 6, pp. 385-391, 2015.

[51] M. B. Shapiro and T. D. France, "The ocular features of Down's syndrome," American Journal of Ophthalmology, vol. 99, no. 6, pp. 659-663, 1985.

[52] D. Karlica, S. Skelin, V. Culic et al., "The ophthalmic anomalies in children with Down syndrome in Split-Dalmatian County," Collegium Antropologicum, vol. 35, no. 4, pp. 1115-1118, 2011.

[53] F. Fimiani, A. Iovine, R. Carelli, M. Pansini, G. Sebastio, and A. Magli, "Incidence of ocular pathologies in Italian children with down syndrome," European Journal of Ophthalmology, vol. 17, no. 5, pp. 817-822, 2007.

[54] A. T. Liza-Sharmini, Z. N. Azlan, and B. A. Zilfalil, "Ocular findings in Malaysian children with Down syndrome," Singapore Medical Journal, vol. 47, no. 1, pp. 14-19, 2006.

[55] B. Stirn Kranjc, "Ocular abnormalities and systemic disease in down syndrome," Strabismus, vol. 20, no. 2, pp. 74-77, 2012.

[56] A. Hestnes, T. Sand, and K. Fostad, "Ocular findings in Down's syndrome," Journal of Mental Deficiency Research, vol. 35, no. 3, pp. 194-203, 1991.

[57] O. H. Haugen, G. Høvding, G. E. Eide, and T. Bertelsen, "Corneal grafting for keratoconus in mentally retarded patients," Acta Ophthalmologica Scandinavica, vol. 79, no. 6, pp. 609-615, 2001.

[58] M. J. Elder, "Leber congenital amaurosis and its association with keratoconus and keratoglobus," Journal of Pediatric Ophthalmology and Strabismus, vol. 31, no. 1, pp. 38-40, 1994.

[59] K. F. Damji, M. M. Sohocki, R. Khan et al., "Leber's congenital amaurosis with anterior keratoconus in Pakistani families is caused by the Trp278X mutation in the AIPLIgene on 17p," Canadian Journal of Ophthalmology, vol. 36, no. 5, pp. 252-259, 2001.

[60] A. G. Karseras and M. Ruben, "Aetiology of keratoconus," The British Journal of Ophthalmology, vol. 60, no. 7, pp. 522-525, 1976.

[61] J. Stoiber, W. H. Muss, J. Ruckhofer, H. Thaller-Antlanger, E. Alzner, and G. Grabner, "Recurrent keratoconus in a patient with Leber congenital amaurosis," Cornea, vol. 19, no. 3, pp. 395$398,2000$.
[62] I. Robertson, "Keratoconus and the Ehlers-Danlos syndrome: a new aspect of keratoconus," The Medical Journal of Australia, vol. 1, no. 18, pp. 571-573, 1975.

[63] U. Beckh, U. Schonherr, and G. O. H. Naumnnn, "Autosomal inherited keratoconus as an ocular symptom of osteogenesis imperfecta tarda Lobstein," Klinische Monatsblatter fur Augenheilkunde, vol. 206, no. 4, pp. 268-272, 1995.

[64] E. Kalkan Akcay, M. Akcay, B. S. Uysal et al., "Impaired corneal biomechanical properties and the prevalence of keratoconus in mitral valve prolapse," Journal of Ophthalmology, vol. 2014, Article ID 402193, 6 pages, 2014.

[65] K. W. Sharif, T. A. Casey, and J. Coltart, "Prevalence of mitral valve prolapse in keratoconus patients," Journal of the Royal Society of Medicine, vol. 85, no. 8, pp. 446-448, 1992.

[66] M. Kosker, N. Arslan, M. Y. Alp et al., "Association between keratoconus and familial mediterranean fever in Turkey," Cornea, vol. 35, no. 1, pp. 77-80, 2016.

[67] E. G. Woodward and M. T. Morris, "Joint hypermobility in keratoconus," Ophthalmic \& Physiological Optics, vol. 10, no. 4, pp. 360-362, 1990.

[68] D. A. Street, E. T. Vinokur, G. O. Waring III, S. J. Pollak, S. D. Clements, and J. V. Perkins, "Lack of association between keratoconus, mitral valve prolapse, and joint hypermobility," Ophthalmology, vol. 98, no. 2, pp. 170-176, 1991.

[69] T. Seiler, S. Huhle, E. Spoerl, and H. Kunath, "Manifest diabetes and keratoconus: a restrospective case-control study," Graefe's Archive for Clinical and Experimental Ophthalmology, vol. 238, no. 10, pp. 822-825, 2000.

[70] I. C. Kuo, A. Broman, A. Pirouzmanesh, and M. Melia, "Is there an association between diabetes and keratoconus?" Ophthalmology, vol. 113, no. 2, pp. 184-190, 2006.

[71] Y. Goldich, Y. Barkana, Y. Gerber et al., "Effect of diabetes mellitus on biomechanical parameters of the cornea," Journal of Cataract and Refractive Surgery, vol. 35, no. 4, pp. 715-719, 2009.

[72] I. Lema and J. A. Durán, "Inflammatory molecules in the tears of patients with keratoconus," Ophthalmology, vol. 112, no. 4, pp. 654-659, 2005.

[73] G. Carracedo, A. Recchioni, N. Alejandre-Alba et al., "Signs and symptoms of dry eye in keratoconus patients: a pilot study," Current Eye Research, vol. 40, no. 11, pp. 1088-1094, 2015.

[74] L. Dienes, H. J. Kiss, K. Perényi et al., "Corneal sensitivity and dry eye symptoms in patients with keratoconus," PLoS ONE, vol. 10, no. 10, Article ID e0141621, 2015.

[75] W. B. Trattler, P. A. Majmudar, J. I. Luchs, and T. S. Swartz, Cornea Handbook, SLACK Incorporated, 2010.

[76] J. G. Hollingsworth, N. Efron, and A. B. Tullo, "In vivo corneal confocal microscopy in keratoconus," Ophthalmic and Physiological Optics, vol. 25, no. 3, pp. 254-260, 2005.

[77] G. Bitirgen, A. Ozkagnici, B. Bozkurt, and R. A. Malik, "In vivo corneal confocal microscopic analysis in patients with keratoconus," International Journal of Ophthalmology, vol. 8, no. 3, pp. 534-539, 2015.

[78] M. C. Mocan, P. T. Yilmaz, M. Irkec, and M. Orhan, "In vivo confocal microscopy for the evaluation of corneal microstructure in keratoconus," Current Eye Research, vol. 33, no. 11-12, pp. 933-939, 2008.

[79] K. H. Weed, C. J. MacEwen, A. Cox, and C. N. J. McGhee, "Quantitative analysis of corneal microstructure in keratoconus utilising in vivo confocal microscopy," Eye, vol. 21, no. 5, pp. 614623, 2007. 
[80] J. C. Erie, S. V. Patel, J. W. McLaren, C. B. Nau, D. O. Hodge, and W. M. Bourne, "Keratocyte density in keratoconus. A Confocal Microscopy Study," American Journal of Ophthalmology, vol. 134, no. 5, pp. 689-695, 2002.

[81] E. Sykakis, F. Carley, L. Irion, J. Denton, and M. C. Hillarby, "An in depth analysis of histopathological characteristics found in keratoconus," Pathology, vol. 44, no. 3, pp. 234-239, 2012.

[82] J. G. Hollingsworth, R. E. Bonshek, and N. Efron, "Correlation of the appearance of the keratoconic cornea in vivo by confocal microscopy and in vitro by light microscopy," Cornea, vol. 24, no. 4, pp. 397-405, 2005.

[83] N. Efron and J. G. Hollingsworth, "New perspectives on keratoconus as revealed by corneal confocal microscopy," Clinical and Experimental Optometry, vol. 91, no. 1, pp. 34-55, 2008.

[84] H. Brewitt, "Light microscope and scanning electron microscope findings in acute keratoconus," Klinische Monatsblatter fur Augenheilkunde, vol. 174, no. 4, pp. 605-613, 1979.

[85] O. Sandali, M. El Sanharawi, C. Temstet et al., "Fourierdomain optical coherence tomography imaging in keratoconus: a corneal structural classification," Ophthalmology, vol. 120, no. 12, pp. 2403-2412, 2013.

[86] R. L. Brautaset, M. Nilsson, W. L. Miller, N. E. Leach, J. H. Tukler, and J. P. G. Bergmanson, "Central and peripheral corneal thinning in keratoconus," Cornea, vol. 32, no. 3, pp. 257261, 2013.

[87] J. H. Mathew, J. D. Goosey, and J. P. G. Bergmanson, "Quantified histopathology of the keratoconic cornea," Optometry and Vision Science, vol. 88, no. 8, pp. 988-997, 2011.

[88] M. W. Scroggs and A. D. Proia, "Histopathological variation in keratoconus," Cornea, vol. 11, no. 6, pp. 553-559, 1992.

[89] R. Yadav, R. Kottaiyan, K. Ahmad, and G. Yoon, "Epithelium and Bowman's layer thickness and light scatter in keratoconic cornea evaluated using ultrahigh resolution optical coherence tomography," Journal of Biomedical Optics, vol. 17, no. 11, Article ID 116010, 2012.

[90] S. Somodi, C. Hahnel, C. Slowik, A. Richter, D. G. Weiss, and R. Guthoff, "Confocal in vivo microscopy and confocal laserscanning fluorescence microscopy in keratoconus," German journal of ophthalmology, vol. 5, no. 6, pp. 518-525, 1996.

[91] Ö. Ö. Uçakhan, A. Kanpolat, N. Ylmaz, and M. Özkan, "In vivo confocal microscopy findings in keratoconus," Eye and Contact Lens, vol. 32, no. 4, pp. 183-191, 2006.

[92] W.-J. Kim, Y. S. Rabinowitz, D. M. Meisler, and S. E. Wilson, "Keratocyte apoptosis associated with keratoconus," Experimental Eye Research, vol. 69, no. 5, pp. 475-481, 1999.

[93] J. T. Barr, K. B. Schechtman, B. A. Fink et al., "Corneal scarring in the Collaborative Longitudinal Evaluation of Keratoconus (CLEK) study: baseline prevalence and repeatability of detection," Cornea, vol. 18, no. 1, pp. 34-46, 1999.

[94] T. Sherwin and N. H. Brookes, "Morphological changes in keratoconus: pathology or pathogenesis," Clinical \& Experimental Ophthalmology, vol. 32, no. 2, pp. 211-217, 2004.

[95] J. H. Mensher, "Corneal nerves," Survey of Ophthalmology, vol. 19, no. 1, pp. 1-18, 1974.

[96] D. V. Patel and C. N. J. McGhee, "Mapping the corneal sub-basal nerve plexus in keratoconus by in vivo laser scanning confocal microscopy," Investigative Ophthalmology \& Visual Science, vol. 47, no. 4, pp. 1348-1351, 2006.

[97] L. Simo Mannion, C. Tromans, and C. O’Donnell, “An evaluation of corneal nerve morphology and function in moderate keratoconus," Contact Lens \& Anterior Eye, vol. 28, no. 4, pp. 185-192, 2005.
[98] N. H. Brookes, I.-P. Loh, G. M. Clover, C. A. Poole, and T. Sherwin, "Involvement of corneal nerves in the progression of keratoconus," Experimental Eye Research, vol. 77, no. 4, pp. 515524, 2003.

[99] R. L. Niederer, D. Perumal, T. Sherwin, and C. N. J. McGhee, "Laser scanning in vivo confocal microscopy reveals reduced innervation and reduction in cell density in all layers of the keratoconic cornea," Investigative Ophthalmology and Visual Science, vol. 49, no. 7, pp. 2964-2970, 2008.

[100] S. Standring, "Gray's anatomy: the anatomical basis of clinical practice," Choice: Current Reviews for Academic Libraries, vol. 42, 2005.

[101] T. Sherwin, N. H. Brookes, I.-P. Loh, C. A. Poole, and G. M. Clover, "Cellular incursion into Bowman's membrane in the peripheral cone of the keratoconic cornea," Experimental Eye Research, vol. 74, no. 4, pp. 473-482, 2002.

[102] S. Sawaguchi, T. Fukuchi, H. Abe, T. Kaiya, J. Sugar, and B. V. J. T. Yue, "Three-dimensional scanning electron microscopic study of keratoconus corneas," Archives of Ophthalmology, vol. 116, no. 1, pp. 62-68, 1998.

[103] K. Van Dijk, V. S. Liarakos, J. Parker et al., "Bowman layer transplantation to reduce and stabilize progressive, advanced keratoconus," Ophthalmology, vol. 122, no. 5, pp. 909-917, 2015.

[104] R. Giugliani, A. Federhen, M. V. M. Rojas et al., "Mucopolysaccharidosis I, II, and VI: brief review and guidelines for treatment," Genetics and Molecular Biology, vol. 33, no. 4, pp. 589604, 2010.

[105] N. Morishige, A. J. Wahlert, M. C. Kenney et al., "Secondharmonic imaging microscopy of normal human and keratoconus cornea," Investigative Ophthalmology \& Visual Science, vol. 48, no. 3, pp. 1087-1094, 2007.

[106] A. Takahashi, K. Nakayasu, S. Okisaka, and A. Kanai, "Quantitative analysis of collagen fiber in keratoconus," Journal of Japanese Ophthalmological Society, vol. 94, no. 11, pp. 1068-1073, 1990.

[107] N. Morishige, R. Shin-Gyou-Uchi, H. Azumi et al., "Quantitative analysis of collagen lamellae in the normal and keratoconic human cornea by second harmonic generation imaging microscopy," Investigative Ophthalmology \& Visual Science, vol. 55, no. 12, pp. 8377-8385, 2014.

[108] J. H. Mathew, J. D. Goosey, P. G. Söderberg, and J. P. G. Bergmanson, "Lamellar changes in the keratoconic cornea," Acta Ophthalmologica, vol. 93, no. 8, pp. 767-773, 2015.

[109] M. Macé, S. D. Galiacy, A. Erraud et al., "Comparative transcriptome and network biology analyses demonstrate antiproliferative and hyperapoptotic phenotypes in human keratoconus corneas," Investigative Ophthalmology and Visual Science, vol. 52, no. 9, pp. 6181-6191, 2011.

[110] R. Joseph, O. P. Srivastava, and R. R. Pfister, "Downregulation of $\beta$-actin gene and human antigen $\mathrm{R}$ in human keratoconus," Investigative Ophthalmology \& Visual Science, vol. 53, no. 7, pp. 4032-4041, 2012.

[111] J. R. Wolter, J. W. Henderson, and E. G. Clahassey, "Ruptures of Descemet's membrane in keratoconus. Causing acute hydrops and posterior keratoconus," American Journal of Ophthalmology, vol. 63, no. 6, pp. 1689-1692, 1967.

[112] J. C. Fan Gaskin, D. V. Patel, and C. N. J. McGhee, "Acute corneal hydrops in keratoconus-new perspectives," American Journal of Ophthalmology, vol. 157, no. 5, pp. 921.el-928.el, 2014.

[113] R. Rajaraman, S. Singh, A. Raghavan, and A. Karkhanis, "Efficacy and safety of intracameral perfluoropropane (C3F 8) 
tamponade and compression sutures for the management of acute corneal hydrops," Cornea, vol. 28, no. 3, pp. 317-320, 2009.

[114] H. Yahia Chérif, J. Gueudry, M. Afriat et al., "Efficacy and safety of pre-Descemet's membrane sutures for the management of acute corneal hydrops in keratoconus," British Journal of Ophthalmology, vol. 99, no. 6, pp. 773-777, 2015.

[115] M.-S. H. El-Agha, Y. M. El Sayed, R. M. Harhara, and H. M. Essam, "Correlation of corneal endothelial changes with different stages of keratoconus," Cornea, vol. 33, no. 7, pp. 707711, 2014.

[116] T. Mimura and N. C. Joyce, "Replication competence and senescence in central and peripheral human corneal endothelium," Investigative Ophthalmology \& Visual Science, vol. 47, no. 4, pp. 1387-1396, 2006.

[117] T. Mimura, S. Yamagami, S. Yokoo, M. Araie, and S. Amano, "Comparison of rabbit corneal endothelial cell precursors in the central and peripheral cornea," Investigative Ophthalmology and Visual Science, vol. 46, no. 10, pp. 3645-3648, 2005.

[118] B. H. Schimmelpfennig, "Direct and indirect determination of nonuniform cell density distribution in human corneal endothelium," Investigative Ophthalmology \& Visual Science, vol. 25, no. 2, pp. 223-229, 1984.

[119] J. Bednarz, A. Rodokanaki-von Schrenck, and K. Engelmann, "Different characteristics of endothelial cells from central and peripheral human cornea in primary culture and after subculture," In Vitro Cellular \& Developmental Biology-Animal, vol. 34, no. 2, pp. 149-153, 1998.

[120] K. Hirata-Tominaga, T. Nakamura, N. Okumura et al., "Corneal endothelial cell fate is maintained by LGR5 through the regulation of hedgehog and Wnt pathway," STEM CELLS, vol. 31, no. 7, pp. 1396-1407, 2013.

[121] S. L. Watson, A. Ramsay, J. K. G. Dart, C. Bunce, and E. Craig, "Comparison of deep lamellar keratoplasty and penetrating keratoplasty in patients with keratoconus," Ophthalmology, vol. 111, no. 9, pp. 1676-1682, 2004.

[122] I. M. Y. Cheung, C. N. J. Mcghee, and T. Sherwin, "A new perspective on the pathobiology of keratoconus: interplay of stromal wound healing and reactive species-associated processes," Clinical and Experimental Optometry, vol. 96, no. 2, pp. 188-196, 2013.

[123] G. Wollensak, E. Spoerl, and T. Seiler, "Riboflavin/ultraviolet-ainduced collagen crosslinking for the treatment of keratoconus," American Journal of Ophthalmology, vol. 135, no. 5, pp. 620-627, 2003.

[124] F. Raiskup-Wolf, A. Hoyer, E. Spoerl, and L. E. Pillunat, "Collagen crosslinking with riboflavin and ultraviolet-A light in keratoconus: long-term results," Journal of Cataract and Refractive Surgery, vol. 34, no. 5, pp. 796-801, 2008.

[125] C. Mazzotta, F. Hafezi, G. Kymionis et al., "In vivo confocal microscopy after corneal collagen crosslinking," Ocular Surface, vol. 13, no. 4, pp. 298-314, 2015.

[126] N. Sharma, K. Suri, S. V. Sehra et al., "Collagen cross-linking in keratoconus in Asian eyes: visual, refractive and confocal microscopy outcomes in a prospective randomized controlled trial," International Ophthalmology, vol. 35, no. 6, pp. 827-832, 2015.

[127] D. P. Piñero and J. L. Alio, "Intracorneal ring segments in ectatic corneal disease-a review," Clinical \& Experimental Ophthalmology, vol. 38, no. 2, pp. 154-167, 2010.

[128] S. Ganesh, R. Shetty, S. D’Souza, S. Ramachandran, and M. Kurian, "Intrastromal corneal ring segments for management of keratoconus," Indian Journal of Ophthalmology, vol. 61, no. 8, pp. 451-455, 2013.

[129] M. Israel, M. O. Yousif, N. A. Osman, M. Nashed, and N. S. Abdelfattah, "Keratoconus correction using a new model of intrastromal corneal ring segments," Journal of Cataract and Refractive Surgery, vol. 42, no. 3, pp. 444-454, 2016.

[130] J. Huelsken and W. Birchmeier, "New aspects of Wnt signaling pathways in higher vertebrates," Current Opinion in Genetics \& Development, vol. 11, no. 5, pp. 547-553, 2001.

[131] P. W. Ingham and A. P. McMahon, "Hedgehog signaling in animal development: paradigms and principles," Genes \& Development, vol. 15, no. 23, pp. 3059-3087, 2001.

[132] S. Takashima, M. Mkrtchyan, A. Younossi-Hartenstein, J. R. Merriam, and V. Hartenstein, "The behaviour of Drosophila adult hindgut stem cells is controlled by Wnt and Hh signalling," Nature, vol. 454, no. 7204, pp. 651-655, 2008.

[133] T. F. Day and Y. Yang, "Wnt and hedgehog signaling pathways in bone development," The Journal of Bone \& Joint SurgeryAmerican Volume, vol. 90, supplement 1, pp. 19-24, 2008.

[134] T. M. Yeung, L. A. Chia, C. M. Kosinski, and C. J. Kuo, "Regulation of self-renewal and differentiation by the intestinal stem cell niche," Cellular and Molecular Life Sciences, vol. 68, no. 15, pp. 2513-2523, 2011.

[135] J. L. Mullor, P. Sánchez, and A. Ruiz i Altaba, "Pathways and consequences: hedgehog signaling in human disease," Trends in Cell Biology, vol. 12, no. 12, pp. 562-569, 2002.

[136] J. Luo, J. Chen, Z.-L. Deng et al., "Wnt signaling and human diseases: what are the therapeutic implications?" Laboratory Investigation, vol. 87, no. 2, pp. 97-103, 2007.

[137] H. Ouyang, Y. Xue, Y. Lin et al., "WNT7A and PAX6 define corneal epithelium homeostasis and pathogenesis," Nature, vol. 511, no. 7509, pp. 358-361, 2014.

[138] G. Cuellar-Partida, H. Springelkamp, S. E. M. Lucas et al., "WNT10A exonic variant increases the risk of keratoconus by decreasing corneal thickness," Human Molecular Genetics, vol. 24, no. 17, pp. 5060-5068, 2015.

[139] G. Cotsarelis, S.-Z. Cheng, G. Dong, T.-T. Sun, and R. M. Lavker, "Existence of slow-cycling limbal epithelial basal cells that can be preferentially stimulated to proliferate: implications on epithelial stem cells," Cell, vol. 57, no. 2, pp. 201-209, 1989.

[140] H. S. Dua, A. Joseph, V. A. Shanmuganathan, and R. E. Jones, "Stem cell differentiation and the effects of deficiency," Eye, vol. 17, no. 8, pp. 877-885, 2003.

[141] X. Gao, D. R. Nannini, K. Corrao et al., "Genome-wide association study identifies WNT7B as a novel locus for central corneal thickness in Latinos," Human Molecular Genetics, 2016.

[142] A. Joseph, P. Hossain, S. Jham et al., "Expression of CD34 and L-selectin on human corneal keratocytes," Investigative Ophthalmology and Visual Science, vol. 44, no. 11, pp. 46894692, 2003.

[143] P. Toti, G. M. Tosi, C. Traversi, K. Schürfeld, C. Cardone, and A. Caporossi, "CD-34 stromal expression pattern in normal and altered human corneas," Ophthalmology, vol. 109, no. 6, pp. 1167$1171,2002$.

[144] L. Brown and H. Wan, "Desmoglein 3: a help or a hindrance in cancer progression?” Cancers, vol. 7, no. 1, pp. 266-286, 2015.

[145] K. Nielsen, S. Heegaard, H. Vorum, K. Birkenkamp-Demtröder, N. Ehlers, and T. F. Orntoft, "Altered expression of CLC, DSG3, EMP3, S100A2, and SLPI in corneal epithelium from keratoconus patients," Cornea, vol. 24, no. 6, pp. 661-668, 2005. 
[146] K. Morton, C. Hutchinson, J. C. Jeanny, I. Karpouzas, Y. Pouliquen, and Y. Courtois, "Colocalization of fibroblast growth factor binding sites with extracellular matrix components in normal and keratoconus corneas," Current Eye Research, vol. 8, no. 10, pp. 975-987, 1989.

[147] Y. Deng, S. Liu, and R. Cai, "Immunohistochemistry research on keratoconus," Yan Ke Xue Bao, vol. 17, no. 2, pp. 65-75, 2001.

[148] B. D. Ashby, Q. Garrett, and M. D. P. Willcox, "Corneal injuries and wound healing - review of processes and therapies," Austin Journal of Clinical Ophthalmology, vol. 1, no. 4, pp. 1-25, 2014.

[149] J. E. Scott and T. R. Bosworth, "A comparative biochemical and ultrastructural study of proteoglycan-collagen interactions in corneal stroma. Functional and metabolic implications," Biochemical Journal, vol. 270, no. 2, pp. 491-497, 1990.

[150] P. Muthiah, H. W. Stuhlsatz, and H. Greiling, "Composition of corneal proteoglycans: density gradient centrifugation and chromatographic studies," Hoppe-Seyler's Zeitschrift fur Physiologische Chemie, vol. 355, no. 2, pp. 924-934, 1974.

[151] J. W. Critchfield, A. J. Calandra, A. B. Nesburn, and M. C. Kenney, "Keratoconus: I. Biochemical studies," Experimental Eye Research, vol. 46, no. 6, pp. 953-963, 1988.

[152] R. Chaerkady, H. Shao, S.-G. Scott, A. Pandey, A. S. Jun, and S. Chakravarti, "The keratoconus corneal proteome: loss of epithelial integrity and stromal degeneration," Journal of Proteomics, vol. 87, pp. 122-131, 2013.

[153] E. L. Cheng, I. Maruyama, N. SundarRaj, J. Sugar, R. S. Feder, and B. Y. J. T. Yue, "Expression of type XII collagen and hemidesmosome-associated proteins in keratoconus corneas," Current Eye Research, vol. 22, no. 5, pp. 333-340, 2001.

[154] K. Wentz-Hunter, E. L. Cheng, J. Ueda, J. Sugar, and B. Y. J. T. Yue, "Keratocan expression is increased in the stroma of keratoconus corneas," Molecular Medicine, vol. 7, no. 7, pp. 470477, 2001.

[155] R. Joseph, O. P. Srivastava, and R. R. Pfister, "Differential epithelial and stromal protein profiles in keratoconus and normal human corneas," Experimental Eye Research, vol. 92, no. 4, pp. 282-298, 2011.

[156] B. Y. J. T. Yue, J. L. Baum, and J. E. Silbert, “The synthesis of glycosaminoglycans by cultures of corneal stromal cells from patients with keratoconus," The Journal of Clinical Investigation, vol. 63, no. 4, pp. 545-551, 1979.

[157] B. García, O. García-Suárez, J. Merayo-Lloves et al., "Differential expression of proteoglycans by corneal stromal cells in keratoconus," Investigative Ophthalmology \& Visual Science, vol. 57, no. 6, pp. 2618-2628, 2016.

[158] B. Y. J. T. Yue, J. L. Baum, and J. E. Silbert, "Synthesis of glycosaminoglycans by cultures of normal human corneal endothelial and stromal cells," Investigative Ophthalmology \& Visual Science, vol. 17, no. 6, pp. 523-527, 1978.

[159] L. Zhou, S. Sawaguchi, S. S. Twining, J. Sugar, R. S. Feder, and B. Y. J. T. Yue, "Expression of degradative enzymes and protease inhibitors in corneas with keratoconus," Investigative Ophthalmology \& Visual Science, vol. 39, no. 7, pp. 1117-1124, 1998.

[160] S. A. Balasubramanian, D. C. Pye, and M. D. P. Willcox, "Are proteinases the reason for keratoconus," Current Eye Research, vol. 35, no. 3, pp. 185-191, 2010.

[161] S. Sawaguchi, B. Y. J. T. Yue, J. Sugar, and J. E. Gilboy, "Lysosomal enzyme abnormalities in keratoconus," Archives of Ophthalmology, vol. 107, no. 10, pp. 1507-1510, 1989.
[162] S. A. Balasubramanian, V. C. Wasinger, D. C. Pye, and M. D. P. Willcox, "Preliminary identification of differentially expressed tear proteins in keratoconus," Molecular Vision, vol. 19, pp. 21242134, 2013.

[163] D. Nelidova and T. Sherwin, Advances in Ophthalmology, InTech, 2012.

[164] R. Visse and H. Nagase, "Matrix metalloproteinases and tissue inhibitors of metalloproteinases: structure, function, and biochemistry," Circulation Research, vol. 92, no. 8, pp. 827-839, 2003.

[165] R. P. Verma and C. Hansch, "Matrix metalloproteinases (MMPs): chemical-biological functions and (Q)SARs," Bioorganic \& Medicinal Chemistry, vol. 15, no. 6, pp. 2223-2268, 2007.

[166] S. A. Collier, "Is the corneal degradation in keratoconus caused by matrix-metalloproteinases?" Clinical \& Experimental Ophthalmology, vol. 29, no. 6, pp. 340-344, 2001.

[167] R. Shetty, A. Ghosh, R. R. Lim et al., "Elevated expression of matrix metalloproteinase- 9 and inflammatory cytokines in keratoconus patients is inhibited by cyclosporine A," Investigative Ophthalmology \& Visual Science, vol. 56, no. 2, pp. 738-750, 2015.

[168] I. Lema, T. Sobrino, J. A. Durán, D. Brea, and E. Díez-Feijoo, "Subclinical keratoconus and inflammatory molecules from tears," British Journal of Ophthalmology, vol. 93, no. 6, pp. 820824, 2009.

[169] S. A. Balasubramanian, S. Mohan, D. C. Pye, and M. D. P. Willcox, "Proteases, proteolysis and inflammatory molecules in the tears of people with keratoconus," Acta Ophthalmologica, vol. 90, no. 4, pp. e303-e309, 2012.

[170] R. B. Whitelock, T. Fukuchi, L. Zhou et al., "Cathepsin G, acid phosphatase, and alpha 1-proteinase inhibitor messenger RNA levels in keratoconus corneas," Investigative Ophthalmology \& Visual Science, vol. 38, no. 2, pp. 529-534, 1997.

[171] S. Sawaguchi, S. S. Twining, B. Y. J. T. Yue, P. Wilson, J. Sugar, and S.-K. Chan, "Alpha-1 proteinase inhibitor levels in keratoconus," Experimental Eye Research, vol. 50, no. 5, pp. 549-554, 1990.

[172] P. Kallinikos, P. Morgan, and N. Efron, "Assessment of stromal keratocytes and tear film inflammatory mediators during extended wear of contact lenses," Cornea, vol. 25, no. 1, pp. 1-10, 2006.

[173] I. Lema, J. A. Durán, C. Ruiz, E. Díez-Feijoo, A. Acera, and J. Merayo, "Inflammatory response to contact lenses in patients with keratoconus compared with myopic subjects," Cornea, vol. 27, no. 7, pp. 758-763, 2008.

[174] G. Carracedo, J. M. González-Méijome, A. Martín-Gil, J. Carballo, and J. Pintor, "The influence of rigid gas permeable lens wear on the concentrations of dinucleotides in tears and the effect on dry eye signs and symptoms in keratoconus," Contact Lens \& Anterior Eye, vol. 39, no. 5, pp. 375-379, 2016.

[175] C. W. McMonnies, "Abnormal rubbing and keratectasia," Eye and Contact Lens, vol. 33, no. 6, part 1, pp. 265-271, 2007.

[176] C. W. McMonnies, D. R. Korb, and C. A. Blackie, "The role of heat in rubbing and massage-related corneal deformation," Contact Lens and Anterior Eye, vol. 35, no. 4, pp. 148-154, 2012.

[177] C. W. M. McMonnies, "Mechanisms of rubbing-related corneal trauma in keratoconus," Cornea, vol. 28, no. 6, pp. 607-615, 2009.

[178] M. Tomita, M. Mita, and T. Huseynova, "Accelerated versus conventional corneal collagen crosslinking," Journal of Cataract and Refractive Surgery, vol. 40, no. 6, pp. 1013-1020, 2014. 
[179] R. Antonios, A. Dirani, A. Fadlallah, E. Chelala, A. Hamadeh, and E. Jarade, "Acute corneal hydrops 3 years after Intra-corneal ring segments and corneal collagen Cross-linking," Middle East African Journal of Ophthalmology, vol. 23, no. 1, pp. 156-159, 2016.

[180] G. Steinwender, L. Pertl, Y. El-Shabrawi, and N. Ardjomand, "Complications from corneal crosslinking for keratoconus in pediatric patients," Journal of Refractive Surgery, vol. 32, no. 1, pp. 68-69, 2016.

[181] G. Labiris, E. Kaloghianni, S. Koukoula, A. Zissimopoulos, and V. P. Kozobolis, "Corneal melting after collagen cross-linking for keratoconus: a case report," Journal of Medical Case Reports, vol. 5, no. 1, article no. 152, 2011.

[182] J. C. Fan Gaskin, I.-P. Loh, C. N. J. McGhee, and T. Sherwin, "An immunohistochemical study of inflammatory cell changes and matrix remodeling with and without acute hydrops in keratoconus," Investigative Ophthalmology and Visual Science, vol. 56, no. 10, pp. 5831-5837, 2015.

[183] E. E. Karaca, M. C. Özmen, F. Ekici, E. Yüksel, and Z. Türkoğlu, "Neutrophil-to-lymphocyte ratio may predict progression in patients with keratoconus," Cornea, vol. 33, no. 11, pp. 1168-1173, 2014.

[184] P. Maier, A. Broszinski, U. Heizmann, D. Böhringer, and T. Reinhard, "Active transforming growth factor- $\beta 2$ is increased in the aqueous humor of keratoconus patients," Molecular Vision, vol. 13, pp. 1198-1202, 2007.

[185] C. Engler, S. Chakravarti, J. Doyle et al., "Transforming growth factor- $\beta$ signaling pathway activation in keratoconus," American Journal of Ophthalmology, vol. 151, no. 5, pp. 752-759, 2011.

[186] J. You, L. Wen, A. Roufas, C. Hodge, G. Sutton, and M. C. Madigan, "Expression of HGF and c-met proteins in human keratoconus corneas," Journal of Ophthalmology, vol. 2015, Article ID 852986, 8 pages, 2015.

[187] F. Jiang, Y. Zhang, and G. J. Dusting, "NADPH oxidasemediated redox signaling: roles in cellular stress response, stress tolerance, and tissue repair," Pharmacological Reviews, vol. 63, no. 1, pp. 218-242, 2011.

[188] A. Behndig, K. Karlsson, B. O. Johansson, T. Brännström, and S. L. Marklund, "Superoxide dismutase isoenzymes in the normal and diseased human cornea," Investigative Ophthalmology \& Visual Science, vol. 42, no. 10, pp. 2293-2296, 2001.

[189] K. A. Wojcik, J. Blasiak, J. Szaflik, and J. P. Szaflik, "Role of biochemical factors in the pathogenesis of keratoconus," Acta Biochimica Polonica, vol. 61, no. 1, pp. 55-62, 2014.

[190] J. Piatigorsky, "Enigma of the abundant water-soluble cytoplasmic proteins of the cornea: the 'refracton' hypothesis," Cornea, vol. 20, no. 8, pp. 853-858, 2001.

[191] A. Pappa, C. Chen, Y. Koutalos, A. J. Townsend, and V. Vasiliou, "ALDH3A1 protects human corneal epithelial cells from ultraviolet- and 4-hydroxy-2-nonenal-induced oxidative damage," Free Radical Biology and Medicine, vol. 34, no. 9, pp. 1178-1189, 2003.

[192] J. E. Downes, P. G. Swann, and R. S. Holmes, "A genetic basis for corneal sensitivity to ultraviolet light among recombinant SWXJ inbred strains of mice," Current Eye Research, vol. 16, no. 6, pp. 539-546, 1997.

[193] S. Agarwal, A. Ghosh, and S. N. Chatterjee, "Spontaneous release of malondialdehyde from ultraviolet light exposed liposomal membranes," Zeitschrift fur Naturforschung. C Journal of Biosciences, vol. 42, no. 5, pp. 585-588, 1987.

[194] R. Buddi, B. Lin, S. R. Atilano, N. C. Zorapapel, M. C. Kenney, and D. J. Brown, "Evidence of oxidative stress in human corneal diseases," Journal of Histochemistry \& Cytochemistry, vol. 50, no. 3, pp. 341-351, 2002.

[195] V. V. Mootha, J. M. Kanoff, J. Shankardas, and S. Dimitrijevich, "Marked reduction of alcohol dehydrogenase in keratoconus corneal fibroblasts," Molecular Vision, vol. 15, pp. 706-712, 2009.

[196] J. D. Lambeth, "NOX enzymes and the biology of reactive oxygen," Nature Reviews. Immunology, vol. 4, no. 3, pp. 181-189, 2004.

[197] H. Wang and I. E. Kochevar, "Involvement of UVB-induced reactive oxygen species in TGF- $\beta$ biosynthesis and activation in keratinocytes," Free Radical Biology and Medicine, vol. 38, no. 7, pp. 890-897, 2005.

[198] A. Van Laethem, K. Nys, S. Van Kelst et al., "Apoptosis signal regulating kinase-1 connects reactive oxygen species to p38 MAPK-induced mitochondrial apoptosis in UVB-irradiated human keratinocytes," Free Radical Biology and Medicine, vol. 41, no. 9, pp. 1361-1371, 2006.

[199] A. Valencia and I. E. Kochevar, "Noxl-based NADPH oxidase is the major source of UVA-induced reactive oxygen species in human keratinocytes," The Journal of Investigative Dermatology, vol. 128, no. 1, pp. 214-222, 2008.

[200] S. R. Atilano, P. Coskun, M. Chwa et al., "Accumulation of mitochondrial DNA damage in keratoconus corneas," Investigative Ophthalmology \& Visual Science, vol. 46, no. 4, pp. 1256-1263, 2005.

[201] M. Chwa, S. R. Atilano, D. Hertzog et al., "Hypersensitive response to oxidative stress in keratoconus corneal fibroblasts," Investigative Ophthalmology \& Visual Science, vol. 49, no. 10, pp. 4361-4369, 2008.

[202] I. Shokolenko, N. Venediktova, A. Bochkareva, G. I. Wilson, and M. F. Alexeyev, "Oxidative stress induces degradation of mitochondrial DNA," Nucleic Acids Research, vol. 37, no. 8, pp. 2539-2548, 2009.

[203] T. Iwamoto and A. G. Devoe, "Electron microscopical study of the fleischer ring," Archives of Ophthalmology, vol. 94, no. 9, pp. 1579-1584, 1976.

[204] X. He, P. Hahn, J. Iacovelli et al., "Iron homeostasis and toxicity in retinal degeneration," Progress in Retinal and Eye Research, vol. 26, no. 6, pp. 649-673, 2007.

[205] A. Loh, M. Hadziahmetovic, and J. L. Dunaief, "Iron homeostasis and eye disease," Biochimica et Biophysica Acta (BBA)General Subjects, vol. 1790, no. 7, pp. 637-649, 2009.

[206] C. Reitz, W. Breipohl, A. Augustin, and J. Bours, "Analysis of tear proteins by one- and two-dimensional thin-layer iosoelectric focusing, sodium dodecyl sulfate electrophoresis and lectin blotting. Detection of a new component: cystatin C," Graefe's Archive for Clinical and Experimental Ophthalmology, vol. 236, no. 12, pp. 894-899, 1998.

[207] P. P. Ward, E. Paz, and O. M. Conneely, "Multifunctional roles of lactoferrin: a critical overview," Cellular and Molecular Life Sciences, vol. 62, no. 22, pp. 2540-2548, 2005.

[208] I. Lema, D. Brea, R. Rodríguez-González, E. Díez-Feijoo, and T. Sobrino, "Proteomic analysis of the tear film in patients with keratoconus," Molecular Vision, vol. 16, pp. 2055-2061, 2010.

[209] S. A. Balasubramanian, D. C. Pye, and M. D. P. Willcox, "Levels of lactoferrin, secretory IgA and serum albumin in the tear film of people with keratoconus," Experimental Eye Research, vol. 96, no. 1, pp. 132-137, 2012.

[210] P. D. Gupta, K. Johar Sr., K. Nagpal, and A. R. Vasavada, "Sex hormone receptors in the human eye," Survey of Ophthalmology, vol. 50, no. 3, pp. $274-284,2005$. 
[211] A. Barbara, Textbook on keratoconus: new insights, Jaypee Brothers Medical Publishers (P) Ltd., 2012.

[212] K. Bilgihan, A. Hondur, S. Sul, and S. Ozturk, "Pregnancyinduced progression of keratoconus," Cornea, vol. 30, no. 9, pp. 991-994, 2011.

[213] F. Hoogewoud, Z. Gatzioufas, and F. Hafezi, “Transitory topographical variations in keratoconus during pregnancy," Journal of Refractive Surgery, vol. 29, no. 2, pp. 144-146, 2013.

[214] B. A. Fink, L. T. Sinnott, H. Wagner, C. Friedman, and K. Zadnik, "The influence of gender and hormone status on the severity and progression of keratoconus," Cornea, vol. 29, no. 1, pp. 65-72, 2010.

[215] J. Glicéria, B. Freitas Valbon, R. Teixeira Santos, R. Ambrosio Jr, and A. Barbara, "Pregnancy-induced progression of keratoconus in a 37-year-old patient," International Journal of Keratoconus and Ectatic Corneal Diseases, vol. 2, pp. 84-88, 2013.

[216] L. D. Pizzarello, "Refractive changes in pregnancy," Graefe's Archive for Clinical and Experimental Ophthalmology, vol. 241, no. 6, pp. 484-488, 2003.

[217] P. S. Soni, "Effects of oral contraceptive steroids on the thickness of human cornea," American Journal of Optometry and Physiological Optics, vol. 57, no. 11, pp. 825-834, 1980.

[218] M. C. Corbett, D. P. S. O’Brart, F. G. Warburton, and J. Marshall, "Biologic and environmental risk factors for regression after photorefractive keratectomy," Ophthalmology, vol. 103, no. 9, pp. 1381-1391, 1996.

[219] M. Tachibana, T. Kasukabe, Y. Kobayashi, T. Suzuki, S. Kinoshita, and Y. Matsushima, "Expression of estrogen receptor $\alpha$ and $\beta$ in the mouse cornea," Investigative Ophthalmology \& Visual Science, vol. 41, no. 3, pp. 668-670, 2000.

[220] E. Spoerl, V. Zubaty, F. Raiskup-Wolf, and L. E. Pillunat, "Oestrogen-induced changes in biomechanics in the cornea as a possible reason for keratectasia," The British Journal of Ophthalmology, vol. 91, no. 11, pp. 1547-1550, 2007.

[221] E. Yuksel, D. Yalinbas, B. Aydin, and K. Bilgihan, "Keratoconus progression induced by in vitro fertilization treatment," Journal of Refractive Surgery, vol. 32, no. 1, pp. 60-63, 2016.

[222] T. B. McKay, J. Hjortdal, H. Sejersen, J. M. Asara, J. Wu, and D. Karamichos, "Endocrine and metabolic pathways linked to keratoconus: implications for the role of hormones in the stromal microenvironment," Scientific Reports, vol. 6, article 25534, 2016.

[223] T. J. Koob, J. J. Jeffrey, A. Z. Eisen, and E. A. Bauer, "Hormonal interactions in mammalian collagenase regulation. Comparative studies in human skin and rat uterus," Biochimica et Biophysica Acta (BBA)—General Subjects, vol. 629, no. 1, pp. 1323, 1980.

[224] G. E. Lang and G. O. H. Naumann, "Keratokonus bei Alagille Syndrom," Klinische Monatsblätter für Augenheilkunde, vol. 198, no. 6, pp. 555-557, 1991.

[225] I. L. Kahán, M. Varsányi-Nagy, M. Tóth, and A. Nádrai, “The possible role of tear fluid thyroxine in keratoconus development," Experimental Eye Research, vol. 50, no. 4, pp. 339-343, 1990.

[226] Z. Gatzioufas and S. Thanos, "Acute keratoconus induced by hypothyroxinemia during pregnancy," Journal of Endocrinological Investigation, vol. 31, no. 3, pp. 262-266, 2008.

[227] S. Thanos, P. Oellers, M. Meyer zu Hörste et al., "Role of thyroxine in the development of keratoconus," Cornea, vol. 35, no. 10, pp. 1338-1346, 2016.
[228] P. M. Yen, "Physiological and molecular basis of Thyroid hormone action," Physiological Reviews, vol. 81, no. 3, pp. 10971142, 2001.

[229] A. J. Coulombre and J. L. Coulombre, "Corneal development: III. The role of the thyroid in dehydration and the development of transparency," Experimental Eye Research, vol. 3, no. 2, pp. 105-114, 1964.

[230] E. Masterson, H. F. Edelhauser, and D. L. Van Horn, "The role of Thyroid hormone in the development of chick corneal endothelium and epithelium," Investigative Ophthalmology \& Visual Science, vol. 16, no. 2, pp. 105-115, 1977. 


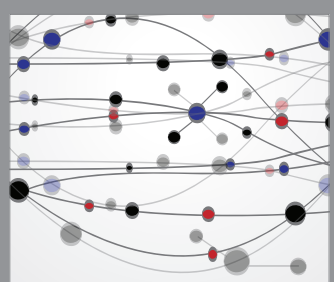

The Scientific World Journal
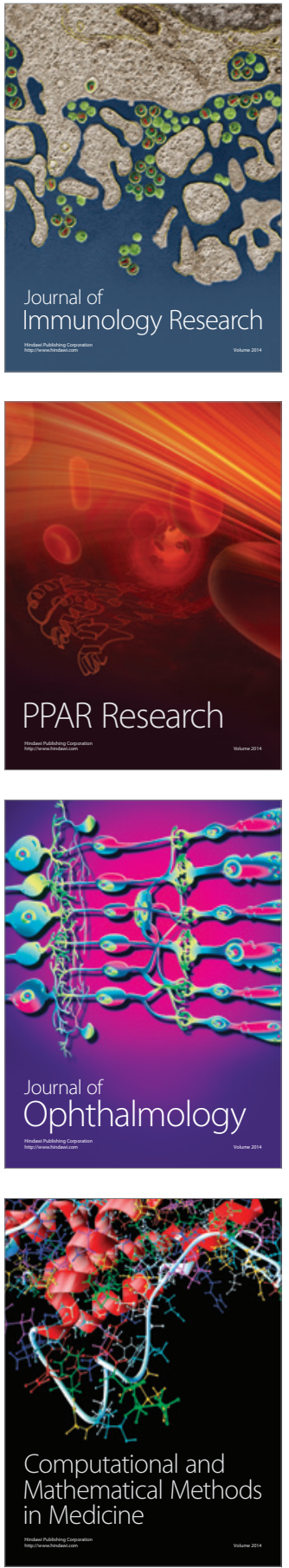

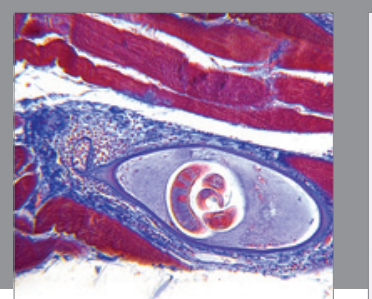

Gastroenterology Research and Practice
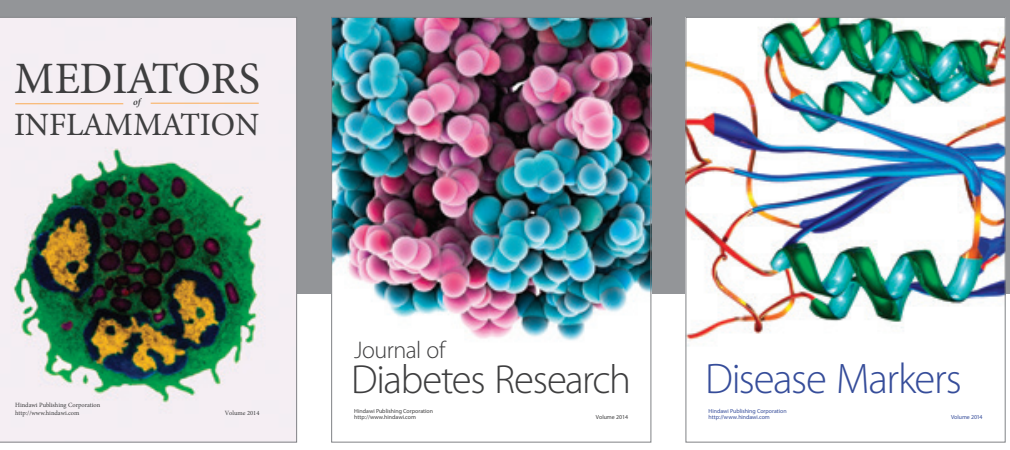

Disease Markers

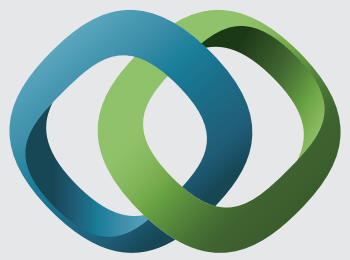

\section{Hindawi}

Submit your manuscripts at

https://www.hindawi.com
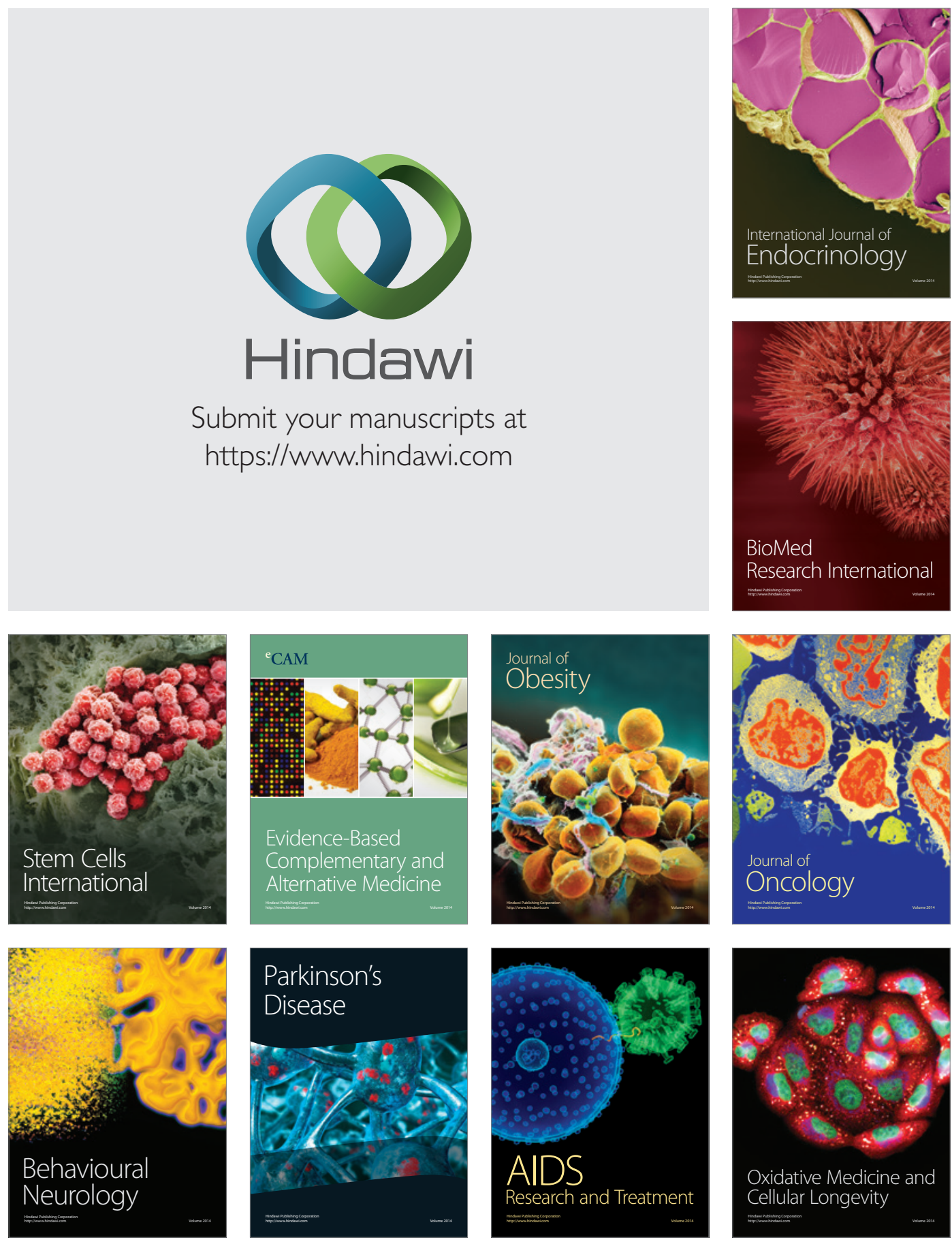